\title{
LA IGUALDAD CONSTITUCIONAL: MÚLTIPLE Y COMPLEJA
}

\author{
CONSTITUTIONAL EQUALITY: MULTIPLE AND COMPLEX
}

\author{
José Manuel Díaz de Valdés J.*
}

\begin{abstract}
RESUMEN: Luego de identificar los elementos y problemas fundamentales de la igualdad, el artículo discurre acerca de las distintas $-y$ no necesariamente excluyentes- variantes que puede adoptar la igualdad constitucional, tanto en su forma como en su contenido. Su forma se vincula a la identificación del obligado; la relación con la ley; su generalidad o especialidad; sus calificaciones, y su presentación como valor/principio y/o derecho individual. Su contenido puede entenderse como la igualdad general o tradicional; como la protección de bienes públicos importantes (derechos fundamentales); como la no discriminación por factores asociados a la pertenencia a ciertos grupos, y como la obligación positiva de promover la igualdad de oportunidades y de facto.
\end{abstract}

Palabras clave: Igualdad, discriminación, igualdad de oportunidades, categorías sospechosas.

ABSTRACT: This article discusses, from the perspective of Constitutional Theory, about several non-necessarily incompatible variants of constitutional equality, both formal and substantive.

Key words: Equality, discrimination, Equal of Opportunity, Suspect Classifications

\section{INTRODUCCIÓN}

La igualdad es uno de los conceptos fundamentales del derecho constitucional, al punto que los más diversos conflictos jurídicos tienden a formularse, al menos parcialmente, en torno a exigencias de igualdad. Lo anterior es particularmente problemático si consideramos que la igualdad es un término sumamente complejo, cuyo contenido varía enormemente en razón de variables tales como la clase de objeto sobre la cual recae; su vinculación a otros principios; influencias ideológicas; la evolución histórica; su uso descriptivo o prescriptivo, y el contexto.

El presente artículo tiene por objeto sentar las bases dogmáticas para el análisis de la igualdad en nuestro sistema constitucional. Dada la escasa doctrina nacional al respecto ${ }^{1}$, se recurre a la teoría constitucional comparada para ampliar la discusión doméstica, mostrando que existen diversas formas de entender la igualdad y sus exigencias, las que si bien

* Doctor en Derecho, Universidad de Oxford. Máster en Derecho, Universidad de Harvard y Universidad de Cambridge. Licenciado y Magíster en Derecho PUC. Profesor de Derecho Constitucional e investigador del Centro de Justicia Constitucional de la Universidad del Desarrollo. Correo electrónico: jdiazdevaldes@udd. cl. Agradezco los comentarios de los profesores Ignacio Covarrubias Cuevas, Sergio Verdugo Ramírez y Nicolás Enteiche Ramírez, así como la colaboración de mi ayudante, señorita Beatriz Vergara M.

1 Entre quienes han escrito en Chile al respecto, destacamos a Fernández (2004); Atria (1997); Vivanco (1999); Nogueira (1997); Figueroa (2000); Bulnes (2009); Leiva (2006); Correa (2011); Espejo (2000). 
pueden entrar en conflicto, arrancan todas de ciertas bases comunes y responden a criterios suficientes de coherencia interna. Del mismo modo, se pretende entregar conceptualizaciones y categorizaciones que contribuyan a clarificar y organizar la argumentación en torno a la igualdad constitucional, convirtiendo un concepto que en ocasiones resulta inmanejable, en una noción jurídicamente más "domesticada".

La hipótesis central de este artículo es que el derecho constitucional, al invocar y hacer suya la noción de igualdad, no puede sino recoger la complejidad intrínseca al concepto. Para comprobar esta hipótesis, el presente artículo reflexiona acerca de las diversas formas en que los ordenamientos jurídicos pueden plasmar y entender la igualdad constitucional. Esta variedad puede ser tanto en la forma como en el contenido. La primera se refiere a cómo la Constitución expresa la idea de la igualdad constitucional, lo que se traduce fundamentalmente en el tipo de cláusulas que utiliza y el lenguaje que ocupa para ello. La segunda trata de los diversos significados que se puede otorgar a la igualdad constitucional, varios de los cuales pueden coexistir en el seno de un mismo ordenamiento.

En cuanto a su estructura, el artículo comienza con algunas reflexiones acerca de la igualdad en general, elaborando un marco conceptual que nos permita luego abordar la igualdad constitucional y cómo esta transforma parcialmente a aquella. A continuación se discurre acerca de las distintas maneras en que la igualdad constitucional puede ser consagrada, tanto en la forma como en el contenido, por los sistemas constitucionales. El artículo finaliza formulando las conclusiones pertinentes.

\section{NOCIONES BÁSICAS DE LA IGUALDAD}

\section{Elementos Esenciales o Comunes}

La igualdad es un concepto que puede ser abordado desde distintas perspectivas, ya sea como una noción descriptiva de la realidad, o como una idea prescriptiva acerca de lo que la realidad debiera ser; como un principio/valor o como un derecho; en términos absolutos o relativos; con un contenido formal o material, etc. Sin embargo, existen ciertos elementos comunes a las distintas formas de entender la igualdad, i.e., i) la existencia de entidades diferentes; ii) la comparación de las mismas de acuerdo a un estándar común que mide una característica compartida por aquellas entidades, y iii) un "agente comparador".

i) Entidades diferentes: La noción de igualdad solo hace sentido cuando nos referimos a dos entidades distintas ${ }^{2}$. Tales entidades pueden ser iguales en muchos aspectos, pero deben ser desiguales en otros, ya que de lo contrario no habría igualdad sino identidad. Por lo mismo, existe la imposibilidad lógica de que la igualdad pueda ser completa ${ }^{3}$. Así, por ejemplo, dos personas pueden ser iguales en su altura o en su coeficiente intelectual, pero desiguales en casi todo lo demás (e.g., ideas, peso, salud, capacidades). Desde esta perspectiva, puede afirmarse que la igualdad entre dos indi-

\footnotetext{
2 Bedau (1967) pp. 6 y ss.; Pérez (2007) pp. 17-18.

3 Westen (1990) pp. 39-40; VAldés (1992) pp. 5-6.
} 
viduos es la excepción, i.e., dos o más personas pueden ser simultáneamente iguales solo en algunos aspectos.

ii) Comparación de acuerdo a un estándar común: Dos entidades son consideradas como iguales cuando comparten una característica que puede medirse de acuerdo a un estándar común. Así, por ejemplo, se puede afirmar que dos personas son iguales porque poseen el mismo coeficiente intelectual sobresaliente, en cuyo caso la característica compartida es ser inteligente, mientras que el test de coeficiente intelectual sería el estándar común. Cabe destacar, sin embargo, que en muchas ocasiones los estándares pueden ser altamente subjetivos, controversiales, e incluso difíciles de identificar (e.g., estándares para medir virtudes o vicios tales como la prudencia o el orgullo).

iii) El agente comparador: Comúnmente se pasa por alto que la igualdad supone que alguien formula el juicio de igualdad/desigualdad basado en la aplicación del estándar común. Es necesario destacar que, en la mayoría de los casos, el resultado de la aplicación de un estándar (i.e., la afirmación de igualdad o desigualdad), dependerá en una medida variable - pero rara vez despreciable- de la discreción del agente que aplica el estándar. Por ejemplo, en matemáticas dos 1 serán iguales a 2 no importando quién haga la comparación. Por el contrario, cuando la cuestión consiste en determinar si un cantante $\mathrm{A}$ es igualmente bueno que un cantante B, la respuesta puede ser diversa dependiendo del agente que realice la comparación. Aunque la discreción del agente puede reducirse y limitarse mediante diversos mecanismos, los que puede ser considerados como "técnicos" o "neutrales" (tales como un test de coeficiente intelectual para comparar la inteligencia, o gráficos de productividad para comparar el desempeño de los empleados), o simplemente "impuestos por la naturaleza” (color de pelo, raza, etc.), el agente retiene una dosis relevante de discreción. En efecto, los agentes comparadores normalmente pueden elegir entre diferentes medios de reducción de la discrecionalidad (o no usarlos en absoluto), y los "factores naturales" no son tan "puros" o "simples" como se podría desear, toda vez que aquellos también son, al menos en parte, construidos socialmente (e.g., conceptos e imágenes de "lo rubio" o "la blancura" pueden variar considerablemente entre diferentes sociedades). Más aún, la discreción del agente aumenta considerablemente si además es libre de elegir el estándar de comparación. Como hemos señalado, la igualdad entre las personas es la excepción, y consecuentemente, la selección del estándar de comparación es crucial para obtener una relación de igualdad entre dos individuos.

\section{Dos Problemas Fundamentales de la Igualdad: Vacuidad y Equivocidad}

\section{A. Vacuidad $^{4}$}

La igualdad ha sido acusada de ser una fórmula vacía, sin contenido real más allá del meramente relacional, por cuanto no provee un criterio sustantivo de comparación (cualquier criterio bastaría para calificar dos entidades de iguales o desiguales). Más aún, aquella

4 Esta idea ha sido desarrollada, entre otros, por WeSTEN (1982) pp. 537-596. 
tampoco otorgaría pista alguna acerca de cómo priorizar entre los distintos estándares de comparación que podrían aplicarse para determinar igualdad o desigualdad en una situación dada. Es así como sería tan válido señalar que dos personas son iguales por el color de sus ojos, el tamaño de sus zapatos o sus convicciones religiosas. Y ello no solo desde una perspectiva descriptiva, sino también desde una normativa. Peor aún, si los resultados de la aplicación de estos estándares difieren entre ellos, no habría forma de determinar si los individuos comparados son iguales o desiguales. A lo más podría afirmarse que dos o más personas son iguales/desiguales en un sentido determinado que compite, o se opone, con otros sentidos en los cuales esas mismas personas son desiguales/iguales.

En consecuencia, resulta indispensable dar contenido a la idea de igualdad con un componente sustantivo, capaz de realizar al menos dos funciones. La primera es limitar el número de estándares de comparación normativamente relevantes. La segunda es otorgar orientación en la priorización de estándares de comparación contradictorios. Ambas funciones exigen, en todo caso, tomar en consideración el contexto específico (básicamente, igualdad de qué e igualdad para qué).

Denominaremos a estos componentes sustantivos "metaprincipios", porque se trata de principios que van más allá de la igualdad strictu sensu. Ejemplos serían las nociones de dignidad $^{5}$; justicia ${ }^{6}$ (en sus diversas facetas, e.g., social, legal, distributiva, como imparcialidad); libertad; solidaridad ${ }^{7}$; autonomía ${ }^{8}$ y participación ${ }^{9}$. Si bien estos ejemplos suponen un alto nivel de abstracción, aquellos pueden ser reformulados en múltiples formas más específicas y contextualizadas. Lo que se mantiene constante, sin embargo, es que cada metaprincipio infunde en la igualdad una perspectiva o "color" distinto.

Si bien los metaprincipios pueden solucionar la vacuidad de la igualdad, ellos a su vez dan lugar a una serie de dificultades. Para comenzar, son varios, y la aplicación de distintos metaprincipios puede arrojar diferentes resultados al cumplir las funciones mencionadas más arriba. Surge entonces la pregunta acerca de cómo seleccionar entre los metaprincipios aplicables al caso. Una posibilidad es jerarquizar, reconociendo la primacía de unos sobre otros en toda circunstancia en que aparezcan conflictos entre ellos, cuestión sumamente implausible dada la importancia de los conceptos mencionados (con la relativa excepción de la dignidad, la cual podría intentar servir de "primer metaprincipio") ${ }^{10}$. Otra posibilidad consiste en establecer jerarquías o prioridades relativas, i.e., diferentes metaprincipios primarían en contextos específicos, solución que presenta la gran dificultad de una delimitación precisa de las áreas sometidas a cada metaprincipio, evitando superposiciones y áreas "abandonadas". Una alternativa diferente sería "maximizar": los metaprincipios serían simultáneamente aplicables tanto como sea posible en la situación concreta. Esta opción, sin embargo, es la más difícil de implementar y obliga a enfrentar problemas

\footnotetext{
5 Véase Réaume (2003); Grant (2007); Feldman (2002) pp. 113 y ss.; Fredman (2001) p. 21.

6 Bedau (1967) p. 18; Valdés (1992) pp. 6 y ss.; Fernández (2004) pp. 30-33; Cea (2012) p. 131. Contrastar con Browne (1978) pp. 48-60.

7 Véase Fredman (2001) p. 3.

8 Cfr. Gardner (1989) pp. 17-22.

9 Véase Fredman (2001) pp. 21-22.

10 Tal vez el caso más evidente sería el alemán. Véase, por ejemplo, Enders (2010) pp. 253-264.
} 
intratables (e.g., ¿pueden los metaprincipios "balancearse" unos contra otros?, ¿debe existir un nivel mínimo de respeto hacia todos los metaprincipios?), todos ellos muy similares a los problemas que surgen a propósito de los conflictos de derechos fundamentales ${ }^{11}$. Finalmente, existe también la posibilidad de utilizar técnicas de interpretación para subsumir, o al menos conciliar, diversos metaprincipios aplicables a un caso concreto.

Las dificultades anteriores se agudizan si consideramos que los metaprincipios son marcadamente valóricos, y por tanto sujetos a fuertes influencias ideológicas y filosóficas que le pueden atribuir significados no solo diversos, sino incluso contradictorios ${ }^{12}$. Más aún, aquellos tienden a ser nociones de textura particularmente abierta, cuyo contenido exacto no es fácil de determinar en muchos contextos. En definitiva, la utilización de metaprincipios, si bien necesaria, es intrínsecamente problemática.

\section{B. Equivocidad}

La noción de igualdad no es unívoca, sino que presenta diversos significados y aproximaciones ${ }^{13}$. Ello explica que las demandas por igualdad varíen enormemente en su contenido, al punto de ser en ocasiones incompatibles.

Lo anterior ha redundado en una enorme cantidad de esfuerzos de categorización y sistematización de tipos o clases de igualdad ${ }^{14}$. En esta sección discutiremos brevemente dos de ellos, uno de carácter más general y otro más preciso, como una forma de ilustrar la equivocidad intrínseca de la igualdad.

Una manera de aproximarse a la igualdad es considerando dos cuestiones complementarias: igualdad de qué e igualdad para qué. La primera asume que las personas no quieren ser iguales en todos los respectos, sino solo en relación a ciertos aspectos o "bienes" en un sentido lato. Esta premisa da lugar a diferentes formas de concebir la igualdad, entre las que destacan la igualdad de trato, la igualdad de oportunidades, la igualdad de resultados, la igualdad de bienestar, igualdad en el respeto y consideración, etc. Volveremos a algunas de estas concepciones más adelante, pero por ahora es importante destacar que aquellas son distintas, y que dan lugar a demandas que pueden coincidir, entrar en conflicto, o sobreponerse en una situación específica.

La segunda cuestión a considerar -la igualdad para qué- da cuenta del hecho que usualmente no se busca la igualdad por la igualdad (salvo quizás en el caso de los igualitarismos más extremos). Si bien la igualdad puede ser valorable en sí misma, lo normal es que aquella sea considerada, conscientemente o no, como un medio para alcanzar otros fines. Esto nos lleva de nuevo a la idea de los metaprincipios explicados previamente (e.g., dignidad, justicia, autonomía), los cuales sirven de metaobjetivos de las demandas de igualdad.

11 Véase Alexy (2002) pp. 50 y ss; Covarrubias (2012) pp. 466-470.

12 Es el caso de la dignidad, véase por ejemplo a RaO (2011) pp. 183-271; MCCrudden (2008) pp. 697-710. En Chile, Covarrubias (2013) pp. 151 y ss.

13 Esta es la problemática central de diversos trabajos, entre ellos RAE (1981); WeSTEN (1990); WILSON (1966); PojMAN Y Westmoreland (1997).

14 Ferrajoli (2010) pp. 73-76; Plamenatz (1967) pp. 83 y ss.; Stanley (1967) pp. 62-64; Figueroa (2009) pp. 29-32. 
Y como ya es evidente, tales metaobjetivos pueden entrar en conflicto, concordar, o superponerse en situaciones específicas.

Los dos tópicos o preguntas recién analizadas -igualdad de qué e igualdad para qué, o si se quiere, el objeto de la igualdad y los metapropósitos de alcanzarla- se combinan en forma diferente en las diversas demandas de igualdad. Más aún, la respuesta a la segunda pregunta también sirve para definir el contenido de la noción de igualdad que aparece en la primera. Así, por ejemplo, la igualdad de oportunidades puede significar cosas muy diferentes según si es considerada como un paso necesario hacia una mayor libertad, o más bien, como un requerimiento de mayor justicia distributiva.

Una categorización complementaria es ofrecida por Rae, quien utiliza cinco factores para distinguir significados de la igualdad. El primer factor es el (los) "sujeto(s) de igualdad"15, el cual permite distinguir entre igualdad individual y grupal. Esta última a su vez puede dividirse en igualdad intragrupal (dentro del mismo grupo) e igualdad intergrupal (entre grupos distintos). Estas nociones de igualdad pueden entrar en conflicto. Es el caso de formas fuertes de discriminación positiva, las cuales buscan lograr una igualdad intergrupal que, sin embargo, afecta la igualdad entre individuos cuando aquellos pertenecen a distintos grupos ${ }^{16}$. Así, por ejemplo, una cuota del $50 \%$ de los cargos públicos para cada sexo pondría en igualdad de condiciones al grupo mujeres con el grupo hombres, pero a la vez podría redundar en desigualdades entre mujeres y hombres específicos. Ello sucedería cuando, para cumplir con la cuota, se desplace a algunos de ellos por miembros del otro grupo, no obstante contar con calificaciones objetivas superiores para el cargo. De forma similar, la igualdad intergrupal puede entrar en conflicto con la igualdad intragrupal. Es así como una medida como la anterior ( $50 \%$ de los cargos públicos para las mujeres), como toda discriminación positiva de ese tipo, produce el fenómeno llamado "creamy layer", según el cual se beneficia a la capa menos desaventajada del grupo desaventajado, produciendo desigualdad intragrupal (todos los grupos, por desaventajados que sean, poseen subgrupos particularmente desaventajados) ${ }^{17}$. Siguiendo con el ejemplo, las mujeres que obtendrían esos trabajos pertenecerían al grupo menos desaventajado de mujeres (i.e., educadas, de estrato social medio o alto, blancas, etc.), lo que a su vez incrementaría la desigualdad dentro del grupo mujeres.

El segundo factor a considerar es el "dominio de la igualdad", i.e., qué es lo que se busca igualar ${ }^{18}$. Aquí la distinción relevante es entre el "dominio de asignación" ("el rango de recursos de que dispone un agente para implementar la igualdad"19) y el "dominio de cuenta" ("el tipo de cuestiones o cosas sobre las que se reclama igualdad" ${ }^{20}$ ). El problema se

\footnotetext{
15 RAE (1981) pp. 20 y ss.

16 Véase a este respecto la sentencia de la Corte Europea de Derechos Humanos Méndez Pérez y otros con España, la que a nuestro juicio no se hace cargo de este problema al referirse a las cuotas electorales por sexo adoptadas en España, confundiendo la igualdad entre individuos con la igualdad entre grupos.

17 Sowell (2004) pp. 23-54 y pp. 186-187; Abram (1983) p. 1323; Eastland (1997) pp. 76-77. Véase también Tushnet (2004) pp. 655-661.

18 RAE (1981) pp. 45 y ss.

19 RAE (1981) p. 48. Traducción propia.

20 RaE (1981) p. 49. Traducción propia.
} 
produce cuando ambos tipos de dominios no coinciden, surgiendo entonces dos demandas distintas de igualdad: una "marginal" y otra "global". La primera reclamará igualar solo los dominios de asignación, aunque los dominios de cuenta se mantengan desigualmente divididos. Por el contrario, la segunda enfatizará la igualación de los dominios de cuenta, utilizando para ello una división desigual de los dominios de asignación (se usa una lógica compensatoria). Lo anterior se puede graficar con la salud pública. Un ejemplo de dominio de asignación sería la cantidad de recursos que el Estado destina a la salud primaria. El dominio de cuenta consistiría, por ejemplo, en la igualdad en el acceso a la atención primaria de salud. Normalmente ambos dominios no coinciden, y en la realidad la atención primaria de salud varía según factores tales como el sector socioeconómico y el territorio geográfico. La igualdad marginal reclamaría que los fondos públicos disponibles que dividan en forma "igual" entre los diversos consultorios, comunas, regiones, etc. Lo mismo para todos. En contraste, la igualdad global reclamaría que los fondos estatales se dividan en forma "desigual", dirigiendo más fondos hacia donde existe peor acceso a la atención primaria de salud, de forma de "igualar" dicho acceso.

Un tercer factor se refiere a la imposibilidad de dividir algunas entidades en forma igual. Surge entonces la noción de igualdad de oportunidades para obtener tales bienes, la que puede a su vez centrarse en las probabilidades o en los medios ${ }^{21}$. La primera apunta a proveer la misma probabilidad de obtener el bien indivisible, mientras que la segunda busca poner a disposición de quienes deseen obtener el bien indivisible los mismos instrumentos. Así, por ejemplo, supongamos que el cargo de gerente general de una empresa se va a adjudicar entre los gerentes de área de la misma empresa. La igualdad de oportunidades puede intentar que todos los candidatos al puesto tengan exactamente la misma chance de obtenerlo (e.g., sorteo aleatorio del cargo), o bien que el cargo sea adjudicado de acuerdo a parámetros objetivos en cuya consecución se ha cuidado que todos tengan las mismas herramientas (e.g. se utiliza el criterio de productividad del área, cuidando que todos los gerentes cuenten con recursos similares, se les provea de información suficiente, se los evalúe por el mismo período de tiempo, etc.). Un problema particular de la igualdad de oportunidades centrada en los medios, sin embargo, es que nunca puede satisfacerse plenamente: siempre se pueden seguir igualando los medios y herramientas que las personas tienen para alcanzar sus fines o bienes. Volveremos a este punto más adelante.

El cuarto factor distingue entre "igualdad de lotes" e "igualdad de personas"22. La primera asume que los individuos son homogéneos y por tanto no considera las características personales, los gustos de las personas, etc. La segunda toma en cuenta las diferencias personales y cómo ellas impactan en el valor que distintos individuos otorgan a los mismos bienes o cosas. Así, por ejemplo, si a mis tres hijos les doy un chocolate idéntico, los estoy tratando como un lote. En cambio, si a cada uno le doy un dulce diferente, según sus propios gustos (e.g., a uno un chocolate, a otro pastillas de miel y a un tercero un helado), estoy aplicando una igualdad de personas. A primera vista, no cabe duda que esta última igualdad sea más perfecta, sin embargo, aquella también presenta dificultades. Es así como

21 RAE (1981) pp. 64 y ss.

22 RaE (1981) pp. 82 y ss. 
la identificación de los elementos que definen el valor que diferentes personas otorgan a un bien puede ser una tarea difícil y a veces imposible, en parte porque pueden ser muy diversos (atendiendo a criterios tales como la utilidad, necesidad, fines personales, etc.), y no visibles para el agente comparador. Además algunos de ellos pueden ser muy controversiales (e.g., odios sectarios, fines destructivos). Y aún si tales fines logran identificarse y son relativamente pacíficos, surge el problema de su medición y comparación: ¿cómo saber la intensidad del gusto de una persona por los chocolates?, ¿y cómo compararla con la aversión de una persona hacia la industria de los helados? Todo esto se complica aún más si consideramos que, dentro de los elementos que impactan en la valoración que una persona da a un bien, se encuentra la pertenencia a ciertos grupos (e.g., miembros de pueblos originarios pueden valorar la propiedad de la tierra en una forma distinta al resto de la población).

Finalmente, Rae distingue entre las demandad por una igualdad absoluta o relativa ${ }^{23}$. La primera exige igualdad total entre individuos, mientras que la segunda reconoce la existencia de grados de igualdad, lo que permite afirmar que una situación A es más igual que una situación B, sin que ninguna de ellas sea completamente igualitaria. Ahora bien, esta igualdad exige criterios de comparación, los cuales pueden o no coincidir, y cuya mayor o menor exigencia dependerá de las características del caso. Ejemplos de tales criterios son considerar más igual cualquier distribución que mejore la condición del sujeto más desaventajado; que aumente la razón o proporción entre quién tiene menos y quién tiene más; que disminuya la diferencia -en términos absolutos- entre quién tiene menos y quién tiene más, o que disminuya lo atribuido al sujeto más aventajado ${ }^{24}$. Cabe destacar, sin embargo, que la posibilidad y factibilidad de comparar igualdades o desigualdades ha sido severamente criticada ${ }^{25}$.

En definitiva, resulta evidente que al hablar de igualdad podemos estar refiriéndonos a cosas muy distintas y aún contradictorias, y es por eso que las demandas de igualdad pueden aparecer como incompatibles o desvinculadas entre sí.

\section{LA IGUALDAD CONSTITUCIONAL}

La igualdad es una de las nociones más importantes del constitucionalismo occidental. Ella no solo sirve de fundamento al régimen democrático de gobierno, sino que también se constituye en una de las bases esenciales del ordenamiento jurídico.

La noción de igualdad, sin embargo, es anterior al derecho constitucional, quien la recepciona. Esta sección discutirá ese proceso de recepción, desarrollando dos tesis principales. La primera es que la constitucionalización de la igualdad supone necesariamente lidiar con los tópicos y dificultades analizadas en la sección II precedente. En otras palabras, el derecho constitucional, al recepcionar la igualdad, le imprime un carácter particular, y desarrolla formas de lidiar con los principales problemas inherentes al concepto. La segun-

\footnotetext{
$23 \operatorname{RAE}(1981)$ pp. 104 y ss.

24 RAE (1981) pp. 110-112

25 Véase, por ejemplo, a Temkin (1986) pp. 102 y ss.
} 
da tesis es que los ordenamientos constitucionales manifiestan formas diversas (y en ocasiones simultáneas), de recepcionar la igualdad, tanto en la forma como en el fondo.

\section{IgUALDAD VERSUS IgUALDAD CONSTITUCIONAL}

En principio, todo lo señalado en la sección II precedente respecto a la igualdad en general es aplicable a la igualdad constitucional. Sin embargo, es necesario realizar ciertos ajustes y precisiones. Es así como señalábamos que la igualdad supone tres elementos esenciales: entidades diferentes; su comparación según un estándar común que mide una característica compartida, y un agente comparador. Todos estos factores se aplican a la noción constitucional de igualdad. Ahora bien, desde la perspectiva del Derecho Constitucional, el punto de partida en materia de igualdad es la proclamación de los seres humanos como fundamentalmente iguales (en nuestro sistema, esta proclamación se encuentra en el artículo $1^{\circ}$ inciso $1^{\circ}$ de la Constitución Política de la República, "CPR”). En otras palabras, se adopta una perspectiva prescriptiva que busca hacer de la igualdad la regla general entre individuos y no la excepción (esta aproximación prescriptiva, sin embargo, invoca como sustento elementos descriptivos, tales como la naturaleza humana o la dignidad). De lo anterior emanan dos corolarios principales. El primero es que la igualdad constitucional "exige un trato similar y solo permite un trato diferente si aquel puede ser justificado por una razón suficiente" 26 . El segundo corolario es que, en caso de duda, la igualdad debe preferirse a la desigualdad. Ambos corolarios han sido llamados, conjunta o separadamente, la "presunción de igualdad"27.

Una segunda precisión que realiza el orden constitucional a los elementos generales de la igualdad es que no toda característica o rasgo de una persona es legalmente relevante, y por lo mismo, no todo estándar de comparación es aceptable. Así, por ejemplo, el color de la piel o el tamaño de las manos difícilmente podrían servir de criterio de comparación para efectos jurídicos. Volveremos a este punto más adelante.

Un tercer ajuste es que el contexto es fundamental para la selección del estándar de comparación, y por lo mismo, la igualdad constitucional exige un grado de conexión (que varía) entre dicho estándar y el propósito de la comparación. Por ejemplo, comparaciones sobre la riqueza de dos personas pueden vincularse fácilmente a la imposición de tributos, pero no con el derecho al voto (si bien esta situación existió en Chile hasta 1888, lo que demostraría que el contexto es sensible a la evolución). La exigencia de este grado de conexión ha tenido su expresión estructurada en la formulación de tests (principalmente razonabilidad y proporcionalidad), cuestión que analizaremos en con mayor detalle en la sección correspondiente.

En la sección precedente también comentamos que la igualdad presenta dos dificultades importantes: su vacuidad y su equivocidad. En relación a la primera, mencionábamos la existencia de metaprincipios capaces de dar contenido a la relación de igualdad. Desde una perspectiva constitucional, la relevancia y naturaleza controversial de los metaprincipios recomiendan su consagración explícita a nivel constitucional. Ello no se restringe solo

26 Alexy (2002) p. 271. Véase también pp. 270-273. Traducción propia.

27 Véase Westen (1990) pp. 230-254; Bedau (1967) pp. 19 y ss. Contrástese con SAdurski (2008) p. 105. 
al texto de la constitución, sino que incluye al proceso que se desarrolla entre aquel y sus principales intérpretes (fundamentalmente el Tribunal Constitucional, los tribunales superiores de justicia y la legislatura). Cabe destacar a este respecto la importancia de considerar a la Constitución como un orden sistemático y coherente de valores y principios, y no solo como un conjunto de reglas. Ese mismo orden es el que permite darle contenido a la igualdad en un sistema constitucional particular. Evidentemente que esto no soluciona todos los conflictos e incertidumbres causados por los metaprincipios (e.g., posibles jerarquías, aplicaciones concurrentes), pero tales problemas son comunes a gran parte del ordenamiento constitucional y no solo a la igualdad constitucional. En otras palabras, las dificultades señaladas se enfrentan desde una perspectiva sistémica, lo que permite obtener orientaciones para identificar el metaprincipio más apropiado para un caso determinado (e.g., en un sistema constitucional particular puede haber una clara preeminencia de la dignidad por sobre otros principios; o en ciertas áreas se puede haber definido que el principio rector es la autonomía).

A nivel más "mecánico", la relación entre metaprincipios e igualdad constitucional también ha desarrollado una expresión estructurada en los tests de igualdad, toda vez que identifican bienes o intereses constitucionalmente protegidos, reconocidos, o al menos tolerados. Los metaprincipios, como mencionábamos, se pueden formular a distintos niveles de abstracción, y dentro del espectro de alternativas pueden presentarse como aquellos bienes o intereses. Así, por ejemplo, el interés superior del niño sería un bien jurídico constitucionalmente protegido que, a su vez, puede presentarse como una reformulación de metaprincipios tales como la dignidad y la autonomía, o incluso como una expresión de justicia.

En relación a la equivocidad de la noción de igualdad, a nivel constitucional se produce un fenómeno similar. En efecto, la igualdad constitucional no es una noción unívo$\mathrm{ca}^{28}$, y es así como los sistemas constitucionales contemporáneos han desarrollado múltiples y coexistentes sentidos para la igualdad. Si bien algunos de ellos se complementan o sobreponen, otros son, al menos parcialmente, antagonistas o incompatibles. Cabe destacar, sin embargo, que el creciente proceso de globalización jurídica ha impulsado los esfuerzos por categorizar, diferenciar y explicar el contenido de las distintas formas de entender la igualdad en los diversos ordenamientos jurídicos nacionales. En otras palabras, desde hace algunos años se ha intentado identificar formas "tipo" o transnacionales de igualdad constitucional, las cuales es posible reconocer en diversos países. Adicionalmente, tales "tipos" de igualdad constitucional se asocian a ciertas cuestiones jurídicas fundamentales, tales como las exigencias que imponen al legislador (o al Estado en general), y su compatibilidad con innovaciones jurídicas polémicas (e.g., discriminación positiva). En la sección III.3 analizaremos algunos de estos tipos de igualdad constitucional.

No obstante lo anterior, nos parece que la precisión más importante que hace la igualdad constitucional en relación a la igualdad en general es su hincapié en la exclusión de la discriminación arbitraria. Desde una perspectiva genérica de la igualdad, las desigualdades por sí mismas no son consideradas como algo malo o incorrecto. En estricto rigor,

28 SAdURSKi (2008) pp. 99 y ss.; Michelman (1986). 
solo se trata de relaciones entre dos entidades distintas que no son iguales en uno o más aspectos. De hecho, tal y como ya mencionamos, la desigualdad es la regla general entre dos individuos, incluso entre aquellos que provienen de grupos relativamente homogéneos. En razón de lo anterior, las demandas de igualdad tienden a utilizar el término discriminación para identificar aquellas desigualdades que no deben ser toleradas. Ahora bien, aunque la noción de discriminación es también un concepto multifacético y equívoco, aquella tiende a asociarse a un trato menos favorable ${ }^{29}$. En otras palabras, se focaliza en el comportamiento del agente comparador en relación a las partes de la relación de igualdad.

La igualdad constitucional, en tanto, ha hecho de la discriminación su preocupación fundamental. Esta preocupación, sin embargo, ha obedecido a grandes variaciones, no solo en el tiempo, sino también en relación a su focalización en ciertas discriminaciones (área, grupos, causales, etc.), y al uso de la legislación especial complementaria (en Chile, principalmente a través de la severamente insuficiente "Ley Zamudio" ${ }^{30}$ ). Algunas de estas variaciones se explican por la adopción de los distintos "tipos" de igualdad transnacional antes mencionados.

No obstante las variaciones señaladas, es posible formular algunas tesis generales. En primer término, la igualdad constitucional considera discriminatoria toda diferencia de trato (positiva o negativa) arbitraria, esto es, que no esté suficientemente justificada ${ }^{31}$. Esto a su vez se vincula a diversas formas de entender la igualdad de trato, y por lo mismo, a distintas maneras de justificar desviaciones a la misma.

En segundo lugar, uno de los efectos fundamentales de la normativa antidiscriminación (tanto constitucional como legal) es limitar, sobre la base de un grupo de valores u objetivos $^{32}$, la libertad del agente comparador, excluyendo algunos estándares de comparación y las características personales que aquellos asumen (al menos en algunos contextos). Además exige un vínculo entre el estándar de comparación y el trato desigual que aquel gatilla, la intensidad del cual varía según el contexto y la jurisdicción.

En tercer término, la normativa antidiscriminación distingue (explícita o implícitamente), entre las diversas causas de la discriminación. Un propósito generalmente claro es la erradicación de los prejuicios y los estereotipos irracionales. Los estereotipos racionales, en cambio, son tolerados a menos que se los prohíba expresamente. La actitud frente a las preferencias es más bien permisiva, salvo respecto de aquellas que se puedan vincular a prejuicios o estereotipos irracionales. Las convenciones sociales son más intensamente revisadas, al menos en ciertos ámbitos, y el juicio acerca de su constitucionalidad puede ser particularmente sensible a la evolución temporal. En todos los casos, sin embargo, la normativa

\footnotetext{
29 Lacey (1987) pp. 416; Feldman (2002) pp. 135 y ss.

${ }^{30}$ Ley 20.609 de 2012 que Establece Medidas contra la Discriminación. Véase mi opinión crítica al respecto en el trabajo Díaz De VALDÉS (2013).

31 Alexy (2002) p. 270; Lacey (1987) p 416; Feldman (2002) pp. 135 y ss.; Fernández (2004) p. 56. Véase también los fallos del Tribunal Constitucional Rol No 28-1985, considerandos 4-8º Rol No 280-1998, considerando $24^{\circ}$, y Rol $N^{\circ} 807-2007$, considerando $22^{\circ}$. A nivel comparado, véase, por ejemplo, las sentencias del Tribunal Constitucional Español STC 22/1981; 34/1981, y 200/2001, así como el fallo de la Corte Suprema Mexicana, AC 2/2002.

32 Ejemplos en Feldman (2002) p. 140.
} 
antidiscriminación se preocupa más de lo que sucede en la esfera pública (e.g., Administración Pública) que en la privada o familiar, donde los agentes gozan de mayor libertad (con la notoria excepción de las relaciones laborales) ${ }^{33}$.

En cuarto lugar, se ha desarrollado una importante distinción entre discriminación directa e indirecta. La primera consiste en el "trato menos favorable que recibe un individuo en razón de una característica personal" 34 tales como el sexo o la raza. Ejemplos serían la exclusión de las mujeres de las Fuerzas Armadas o reservar ciertos cargos públicos a los miembros de una determinada religión o etnia. La discriminación indirecta es un desarrollo posterior ${ }^{35}$ y "prohíbe prácticas que formalmente se aplican a todos pero que tienen el efecto de afectar negativamente a individuos pertenecientes a ciertos grupos protegidos, a menos que pueda demostrarse que tales prácticas pueden ser objetivamente justificadas por un fin legítimo que es perseguido por medios apropiados y necesarios" ${ }^{\text {"3 }}$. Sería el caso de una norma que exige 1,80 metro de altura para postular al cargo de Rector de una universidad. A primera vista, la regla es neutra, pero en el contexto chileno dicha regla tendría por efecto la exclusión desproporcional de mujeres y miembros de pueblos originarios, sin que exista una razón suficiente que vincule el cargo a la exigencia de altura.

Finalmente, cabe destacar que la igualdad constitucional no intenta abarcarlo todo. En otras palabras, no todas las desigualdades son objeto de prohibición constitucional. Algunos factores que inciden en esta materia son el área en que se produce la desigualdad (e.g. vida familiar), y el factor de discriminación (e.g., nacionalidad). Una clasificación que puede resultar útil a este respecto es la que distingue entre desigualdades naturales o biológicas, y aquellas de carácter social. Las primeras son innatas y virtualmente imposible de alterar (e.g., inteligencia, sexo). Las segundas son socialmente construidas y podrían ser alteradas (e.g., pobreza, clase social). Tradicionalmente, la normativa antidiscriminación intenta remover al menos algunas de las desigualdades sociales (otras pueden considerarse justificadas e incluso necesarias ${ }^{37}$ ), pero solo (en el mejor de los casos) compensar por las naturales o biológicas ${ }^{38}$. En todo caso, esta distinción presenta una limitación importante, ya que a muchas características biológicas se les otorga un significado social que es precisamente el que las convierte en una fuente de discriminación. Así, por ejemplo, tener piel oscura es una desigualdad biológica, pero lo que convierte este rasgo en discriminatorio (generando una desigualdad relevante para el derecho) es la interpretación social de ese rasgo como algo negativo, inferior o no deseable.

\section{La Dimensión Formal de la Igualdad Constitucional}

La gran mayoría de las constituciones incluyen cláusulas de igualdad. Aunque existen grandes similitudes entre ellas, también se aprecian diferencias importantes, las que

\footnotetext{
33 LOURY (1987) p. 259.

34 Mccrudden y Prechal (2009) p. 28. Traducción propia. Véase también Mccrudden (1994) pp. 2-19.

35 Véase Westen (1990) pp. 108-113; Fredman (2001) pp. 23 y ss.; Mccrudden (1994) pp. 20-31.

36 Mccrudden y Prechal (2009) pp. 35 y ss. Traducción propia.

37 Bedau (1967) pp. 21-24; RaWls (1999) pp. 47-101; Green (1998) p. 15.

38 Alexy (2002) p. 262. Contrastar con Buchanan (1995).
} 
pueden incidir en su interpretación y aplicación. En otras palabras, la forma de estas cláusulas puede condicionar el contenido sustancial de la igualdad constitucional. En esta sección discutiremos cinco variaciones formales que nos parecen particularmente relevantes.

\section{A. ¿Quién es el obligado?}

El primer aspecto formal a considerar es el sujeto a quien se dirige la cláusula de igualdad, i.e., quien tiene el deber de respetar el mandato de igualdad. Este factor es relevante, entre otras razones, porque impacta o condiciona la exigibilidad de dicho mandato. Es así como en algunos casos el destinatario es indeterminado en el texto (e.g., "los individuos nacen libre e iguales en dignidad y derechos"). En otros puede ser la ley (igualdad en la ley), el Estado y sus organismos (e.g., igualdad en el acceso a los tribunales de justicia), u otros ciudadanos (e.g., no discriminación en las relaciones laborales).

El primer tipo es el más amplio, pero ofrece menores posibilidades de exigencia directa. Los tribunales, sin embargo, siempre pueden utilizar estas cláusulas como un principio general de interpretación constitucional, otorgándole por esa vía cierta exigibilidad.

Identificar a la ley como destinatario es una de las formas más clásicas de formular la igualdad constitucional, no obstante que el sometimiento efectivo del legislador a esta garantía es una conquista relativamente reciente ${ }^{39}$. Si bien su ámbito de aplicación continúa siendo amplio, existe suficiente determinación respecto al sujeto (legislador) y al acto (ley) que cubre el mandato de igualdad, lo que facilitaría su exigibilidad.

Cuando el destinatario es el Estado en general (artículo $19 \mathrm{~N}^{\circ} 2$ de la CPR) o alguno de sus organismos en particular (e.g., Banco Central en el artículo 109 de la CPR), el mandato puede o no asociarse a derechos particulares (e.g., igualdad en la repartición de los tributos). En el primer caso, la situación es similar al párrafo precedente. En el segundo, la vinculación a un derecho específico debiera allanar la mayor exigibilidad de la cláusula.

Finalmente, la última variedad corresponde a una visión o aplicación horizontal de los derechos constitucionales. Su nivel de exigibilidad dependerá de varios factores, tales como la naturaleza de las acciones procesales disponibles, así como del contexto en que se invoque (e.g., su exigibilidad sería más probable en el ámbito laboral que en el familiar).

\section{B. Conexión entre las palabras "igualdad" y "ley"}

Un segundo aspecto a considerar en la redacción de las cláusulas constitucionales de igualdad se refiere exclusivamente a aquellos casos en que se invoca expresamente a la ley, sea que su destinatario sea el legislador u otras autoridades públicas. Estas cláusulas pueden formularse como igualdad ante la ley, en la ley, en la aplicación de la ley, o de alguna forma similar, redacción que, en principio, puede vincularse al tipo de demanda de igualdad al que la constitución quiere dar respuesta.

Una alternativa es que la demanda de igualdad consista en que la ley no reconozca la preexistencia en la sociedad de castas sujetas a tratos privilegiados o desaventajados. Consagra así no solo la libertad del legislador frente a un sistema social fuertemente estratificado (e.g., India; Francia del Anciene Regime), sino que también refuerza el compromiso en su

39 Soberanes (2011) pp. 20 y ss.; AleXy (2002) pp. 260-262. 
desmantelamiento. Esta demanda queda mejor reflejada por la igualdad ante la ley, ya que los individuos no podrían invocar privilegios preexistentes frente al legislador.

Una segunda demanda de igualdad consiste en que la ley no cree grupos privilegiados o desaventajados. Ello no significa que la ley no pueda hacer distinciones, pero estas deben ser justificables en base a razonamientos distintos que la mera pertenencia a un grupo. En contraste con la primera demanda, aquí la libertad del legislador no se amplía, sino que se restringe. Esta alternativa se asocia a la idea de igualdad en la ley, i.e., las personas son iguales en el contenido de la ley.

Una tercera alternativa se refiere a que la ley se aplique solo a las personas y situaciones cubiertas por ella y no a otras (y viceversa) ${ }^{40}$. Si bien se trata de una afirmación que podría calificarse de tautológica, su objeto es restringir el comportamiento de las autoridades públicas, impidiendo la aplicación abusiva de una norma más allá del ámbito para el que se dictó, así como la reducción arbitraria del mismo a menos de lo que se suponía que la ley regularía. Cabe destacar que esta demanda se relaciona más claramente con la igualdad en la aplicación de la ley, y no se dirige al legislador, sino que a las autoridades llamadas a aplicar la ley (fundamentalmente la Administración y los jueces).

Finalmente, un cuarto tipo de demanda de igualdad consiste en que la ley se aplique por parte de las autoridades públicas "con la misma mano". Esta es una demanda más exigente que la anterior, por cuanto no bastaría aplicar la norma cuando corresponde, sino que se requeriría una cierta similitud en las calidades de esa aplicación (intensa, estricta, laxa, etc.). Tal y como en el caso anterior, el destinatario del mandato constitucional no es el legislador sino que otras autoridades estatales, y suele denominarse igualdad en la aplicación de la ley.

Sin perjuicio de lo señalado, cabe destacar que la igualdad ante la ley podría considerarse como como la redacción más general de entre las mencionadas, al punto de poder incluir -eventualmente- todos los otros sentidos ya explicados, con la probable excepción del último (aplicación de la ley "con la misma mano") ${ }^{41}$.

\section{Cláusulas generales o especiales}

Una tercera variación formal de las cláusulas de igualdad se refiere a su amplitud. Es así como existen cláusulas generales que mandatan la igualdad con ninguna o escasa especificación, por ejemplo, "todos las personas son iguales”. En contraste, las cláusulas especiales de igualdad contienen importantes precisiones. Las más comunes son aquellas que se refieren a ciertas áreas o materias (e.g., laboral, política, tributaria), así como las que establecen "categorías sospechosas", i.e., características o rasgos personales que, como regla general, no deben utilizarse para establecer diferencias entre individuos, tales como la raza, el sexo, la religión, la opinión política, etc. (e.g. artículo $19 \mathrm{~N}^{\circ} 16$ de la CPR).

Las cláusulas específicas de igualdad normalmente causan dos dificultades importantes. La primera consiste en determinar su relación con las cláusulas generales de igualdad: ¡son las primeras iteraciones simbólicas de la regla general aplicadas a contextos particu-

\footnotetext{
40 Véase Westen (1990) pp. 185 y ss.; Réaume (2003) p. 648; Sadurski (2008) pp. 94 y ss.

41 Véase Alexy (2002) pp. 260-262.
} 
lares, o contienen un contenido normativo de igualdad distinguible? ¿Deben considerarse como una excepción a la provisión general de igualdad o como una modulación de la misma que redefine su contenido? ${ }^{22}$ Esto último dependerá, al menos en parte, del contenido atribuido a las cláusulas generales de igualdad. En efecto, si estas se consideran como exclusivamente formales, las cláusulas específicas pueden ser consideradas como una apertura o sustento constitucional hacia formas más sustantivas y demandantes de igualdad.

La segunda dificultad es propia de aquellas cláusulas especiales que establecen categorías sospechosas, y consiste en determinar si las características o rasgos enumerados constituyen una lista abierta o cerrada. Y si es abierta, la siguiente pregunta es qué otras características o rasgos pueden ser incluidos en la lista, lo que a su vez presupone que es posible identificar un criterio (extraíble del conjunto de características listadas explícitamente) que pueda servir para expandir la enumeración a nuevas características. Ejemplos de tales criterios son la desventaja histórica; el estatus de minoría; la inmutabilidad del factor en cuestión, y la protección de la dignidad humana ${ }^{43}$.

En todo caso, las cláusulas específicas de igualdad, y en especial las que establecen categorías sospechosas, tienden a asociarse a un escrutinio judicial más estricto que el aplicable a cláusulas generales de igualdad ${ }^{44}$. En otras palabras, debido a que la Constitución demuestra una preocupación especial frente al empleo de estas "categorías sospechosas" para hacer distinciones, aquel debe ser particularmente bien justificado.

\section{D. ¿Qué tipo de igualdad?}

La cuarta distinción formal se refiere a cláusulas constitucionales que ocupan la voz "igualdad" sin adjetivos, en contraste con aquellas que se refieren a igualdad "real", "efectiva", "sustancial", "de oportunidades", o similar. Las primeras reflejan la redacción más tradicional, mientras que las segundas van aumentando gradualmente durante el siglo XX.

A primera vista, podría pensarse que las cláusulas tradicionales y "simples" de igualdad apuntan a una visión formalista y minimalista del mandato constitucional, el cual se tendía a confundir con la generalidad, abstracción y "neutralidad" de las normas jurídicas (volveremos a este punto en la sección siguiente). Por el contrario, las cláusulas más "complejas” evidenciarían la voluntad del constituyente de ir más lejos, mandatando la aplicación de una igualdad más exigente. Un análisis más cuidadoso, sin embargo, nos lleva a pensar que el aspecto formal, si bien importante, no es necesariamente determinante. Es así como las cláusulas tradicionales o "simples" de igualdad, aun cuando hayan sido el reflejo de una visión minimalista del mandato constitucional, no necesariamente operan como límites a visiones más ambiciosas. Más aún, tales cláusulas pueden mutar o interpretarse de forma de dar cabida nuevas exigencias de igualdad.

\footnotetext{
${ }_{42}$ A este respecto, la evolutiva incorporación de la paridad sexual en la constitución francesa es ilustrativa. Véase, por ejemplo, los fallos del Consejo Constitucional Francés CC 2001/445 y 2006/533.

43 Véase Réaume (2003) pp. 660-661; Huscroft (2000) p. 704.

${ }^{44}$ Mccrudden y Prechal (2009) pp. 23-25; Atria (1997) pp. 64-71. Véase también Sadurski (2008) pp. 111-124, y su crítica a considerar el uso de estas categorías como siempre discriminatorias. En el ámbito jursisprudencial, véase la sentencia del Tribunal Constitucional Español STC 200/2001, el cual se remite a diversos precedentes en la materia.
} 
No obstante lo anterior, la formulación explícita de cláusulas formalmente más complejas puede constituir una ventaja. Ello no solo por los problemas teóricos asociados a la mutación e interpretación constitucional (e.g., déficit democrático, falta de capacidad, ilegitimidad por contrariar el poder constituyente originario), sino también por dificultades de orden práctico. En así como las mutaciones o interpretaciones constitucionales pueden ser difíciles de identificar y consolidar, sin contar con la constante posibilidad de revisión y modificación, e incluso de reversión a mandatos más minimalistas de igualdad. Es por ello que las cláusulas "complejas" de igualdad (las que normalmente se adicionan -no sustituyen- a las cláusulas "simples" o tradicionales), otorgan una base más sólida y directa para demandas de igualdad más ambiciosas. Un buen ejemplo al respecto es el artículo 9.2 de la Constitución española, el cual se refiere explícitamente a una igualdad "real y efectiva", lo que ha permitido al Tribunal Constitucional de ese país justificar la constitucionalidad de las cuotas electorales para mujeres ${ }^{45}$.

\section{E. Igualdad como valor/principio o como derecho positivo/negativo}

Finalmente, la redacción de las cláusulas constitucionales de igualdad varía entre aquellas que la tratan como un principio y/o valor general de derecho constitucional, y las que se refieren a un derecho individual a la igualdad. También es común que un ordenamiento contemple ambos tipos de cláusulas simultáneamente ${ }^{46}$.

Tratar la igualdad como principio o valor implica, entre otras cosas, que aquella sirve como un estándar de evaluación de normas y actos jurídicos, como inspirador de los mismos, e incluso como criterio de interpretación ${ }^{47}$. En cambio, establecer la igualdad como un derecho implica, a lo menos, la imposición de límites a la actividad de las autoridades públicas (dimensión negativa). Adicionalmente puede requerir la promoción de la igualdad por parte de tales autoridades (dimensión positiva), o extender a los otros particulares la obligación de respeto o no vulneración (horizontalidad del derecho). Establecer la igualdad como derecho conlleva también el proveer acciones jurisdiccionales de protección directa.

Tal y como en el caso de la letra d) precedente, la consagración de solo una de las dimensiones señaladas no es un obstáculo infranqueable para el desarrollo de la otra. En efecto, más allá del formalismo y "literalismo" propio de sistemas jurídicos como el nuestro, la dogmática constitucional contemporánea tiende a reconocer la naturaleza compleja de ciertos bienes jurídicos, los que simultáneamente pueden operar como derechos y principios o valores.

\section{La Dimensión Sustancial de la Igualdad Constitucional}

Como mencionáramos previamente, la igualdad constitucional no es una noción unívoca. Es así como, al margen de la formalidad de las respectivas cláusulas (aunque probablemente influenciados por ella), los sistemas constitucionales contemporáneos han desa-

\footnotetext{
45 Véase los fallos del Tribunal Constitucional Español STC 12/2008 y 13/2009.

46 El caso típico es el español, véase Pérez (2007) pp. 83 y ss.; Martínez (2000) pp. 25-90; FernÁNdez (2004) pp. 34-42.

47 Valdés (1992) p. 18; Pérez (2007) pp. 84 y ss.; Fernández (2004) pp. 34 y ss.; Alexy (2002) pp. 86 y ss.
} 
rrollado diferentes nociones de igualdad. Más aún, es normal que varias de tales nociones coexistan simultáneamente dentro de un sistema, pudiendo complementarse, sobreponerse, y en ocasiones entrar en conflicto.

En la presente sección analizaremos distintas formas de entender la igualdad constitucional, para lo cual seguiremos en lo fundamental la clasificación de carácter práctico desarrollada por McCrudden y Prechal ${ }^{48}$, la cual ha sido modificada parcialmente, suplementada y desarrollada de acuerdo a literatura complementaria y a las ideas del autor.

\section{A. Igualdad General}

La igualdad general se funda en el entendimiento tradicional de la igualdad, el que se vincula a la fórmula aristotélica que manda tratar igual a los iguales (personas/casos) y desigual a los desiguales ${ }^{49}$. La definición consta de dos partes. Mientras la primera exige un tratamiento idéntico para asegurar la igualdad, la segunda requiere un tratamiento diverso para alcanzar el mismo objetivo. Cualquier desviación de estas reglas, para no ser arbitraria, debe justificarse como "racional" o "razonable".

En términos formales, la igualdad general se encuentra normalmente asociada a cláusulas constitucionales generales (e.g., "todas las personas nacen libres"), y por lo mismo no se encuentra limitada a materias o áreas específicas (e.g., igualdad racial o sexual). Adicionalmente, esta noción de igualdad sirve de "punto de partida" o base para las demás concepciones de igualdad y es autónoma, en el sentido que puede invocarse directamente sin necesidad de vincularla a otro derecho fundamental (e.g., igualdad en el ejercicio del derecho a la libertad religiosa).

Cabe destacar que la igualdad general es la forma más establecida, extendida y común de entender la igualdad, así como la más popular y fácil de aplicar por los tribunales ${ }^{50}$. Aquella refleja la idea fundamental de que la Constitución considera a los individuos como esencialmente iguales, y por lo mismo, merecedores de un trato igualitario ${ }^{51}$. En algunas jurisdicciones (e.g., Francia, España, México), esta noción de igualdad se confundía originalmente con la generalidad y la abstracción de la ley ${ }^{52}$. Es decir, la manera de asegurar un tratamiento igualitario por parte de la ley era redactándola de forma que se dirigiera a la población en su conjunto, y no a individuos específicos o grupos de personas ${ }^{53}$. A su vez, lo anterior se relacionaba a la idea de "ceguera de la ley", vale decir, la convicción de que las

48 Mccrudden y Prechal (2009). Ejemplos de otras clasificaciones doctrinarias en Ferrajoli (2010) pp. 73 yss.; Pérez (2007) pp. 22 y ss.; Fredman (2008) pp. 178-179.

49 Mccrudden y Prechal (2009) pp. 11 y ss. La referencia a Aristóteles es a Ética a Nicómaco, Libro V..

50 En Chile el Tribunal Constitucional la ha utilizado continuamente. Véase, por ejemplo los fallos Rol $\mathrm{N}^{\circ}$ 1254-08, considerando 46; Rol No 219-95, considerando 17; Rol No 811-07, considerando 18, y Rol $\mathrm{N}^{\circ}$ 1951-11, considerando 15. En derecho comparado, véase, por ejemplo, las sentencias de la Corte Suprema mexicana ADR 988/2004; 537/2006; AR 1959/2004; 1629/2004; 846/2006, y 55/2006.

51 Stanley (1967) p. 63. Contrastar con Westen (1990) p. 123.

52 En Chile, véase, por ejemplo, TC Rol 986-07, considerando 29.

53 Pérez (2007) p. 22 
características personales de los individuos (e.g., raza, sexo) deben ser, como regla general, irrelevantes para el sistema jurídico ${ }^{54}$.

La noción tradicional de igualdad, sin embargo, presenta diversos inconvenientes. Es así como se la ha acusado de "formal”, "vacía” o tautológica”, en parte porque no provee (al menos directamente) criterios sustanciales para determinar qué es igual o desigual ${ }^{55}$. En otras palabras, la fórmula aristotélica nos dice qué hacer cuando dos cosas son iguales o desiguales, pero no nos ayuda en el proceso previo de determinar si ellas son o no iguales. La selección del estándar de comparación que contestará esa pregunta precede la aplicación de la regla aristotélica, y depende de los metaprincipios que "den contenido" a la igualdad, tal y como se explicó en la sección II.2.a) precedente.

Otro inconveniente importante de la igualdad general consiste en el test de racionalidad que se utiliza para determinar si las desviaciones a la misma son justificadas. Aquel puede variar enormemente entre distintas jurisdicciones, e incluso dentro del mismo sistema jurídico. Su exigencia puede ir desde la sola alegación de una razón que excluya el mero capricho, hasta el examen de plausibilidad de las razones dadas, pasando por su efectividad, y llegando incluso a examinar la razonabilidad o capacidad de persuasión de las mismas. La estructura del test también varía. Una forma de concebirlo es dividirlo en dos partes. Una de ellas examina la relación existente entre la desviación presentada y los objetivos o fines que se buscan lograr con la medida. Así, por ejemplo, la imposición de tributos diferentes con el objeto de lograr una mayor justicia distributiva parece ser razonable, situación que cambia si se intenta justificar coberturas desiguales en la salud pública con el objeto de elevar la calidad de la educación. Aquí no existe una conexión suficiente que satisfaga la exigencia de racionalidad. La segunda parte del test analiza la relación entre el criterio o estándar utilizado para determinar la igualdad o desigualdad de dos entidades y la consecuente desviación a la igualdad general. En el ejemplo anterior, sería racional imponer impuestos diferentes a las personas de acuerdo a su fortuna, pero no en relación a su estatura. Otra forma de concebir el test de razonabilidad es como un análisis único (no en dos partes) de la relación entre tres elementos: quién es el afectado por la desviación, cuál es desviación, y cuál es el propósito de dicha desviación. Este análisis, a su vez, puede suponer la utilización de diversas metodologías para identificar los estándares de comparación, los propósitos involucrados, las relaciones de causalidad, etc.

En síntesis, resulta equivocado considerar la racionalidad como un test homogéneo, más allá de la modesta apreciación de que se trata de un estándar judicial relativamente laxo, en particular si se lo compara con la proporcionalidad. Tal vez la función más relevante que el test de racionalidad no cumple es comparar y elegir entre estándares de comparación cuya aplicación arroja la igualdad entre dos entidades, y aquellos estándares que resultan en la desigualdad entre las mismas entidades. En otras palabras, el test no ayuda a decidir si las razones para tratar a dos personas en forma diferente son más fuertes o más débiles que aquellas para tratarlas de la misma manera. La lógica del test funciona en

\footnotetext{
54 Véase también Mccristal (1994) p. 166; Green (1998) p. 126; Loury (1987) pp. 253-259. Contrastar con POST (2002) pp. 1-40.

55 Westen (1990) pp. 185-229; Alexy (2002) pp. 264-265; Sunstein (1994) pp. 2422 y ss.
} 
forma diferente: el tratamiento igualitario es la regla de normalidad, y para escapar de la misma solo se requiere cierta racionalidad. Más aún, la racionalidad no exige una relación estrecha entre el criterio o estándar utilizado para diferenciar, la diferencia realizada, y los fines u objetivos perseguidos. Variables grados de causalidad son tolerados, al igual que la "sobreinclusión" (overinclusiveness) o "infrainclusión" (underinclusiveness). Estos fenómenos se producen, respectivamente, cuando el criterio de selección incluye algunas situaciones o personas que debieron excluirse de acuerdo a los fines invocados, o cuando excluye algunas situaciones o personas que debieran estar comprendidos de acuerdo a tales fines ${ }^{56}$. Así, por ejemplo, si el Estado de Chile, con el objetivo de proteger la cultura y particularidades de la cultura Rapa Nui, prohíbe a quienes residen en "el continente" radicarse en Isla de Pascua, la medida sería "sobreinclusiva" en la medida que comprendería a los miembros de la cultura Rapa Nui que residen en el continente, e "infrainclusiva” en cuanto no comprendería a los extranjeros. Bajo un test de razonabilidad, tales problemas requieren de una entidad y/o intensidad muy significativas para invalidar la diferencia de trato.

Adicionalmente, en relación a los fines u objetivos, incluso si una versión más estricta del test de racionalidad fuera más allá de los propósitos declarados e intentase identificar los fines y objetivos "reales" de la diferencia de trato, aquellos no serán comparados o priorizados. Simplemente se los aceptará mientras sean legítimos y estén suficientemente conectados con la diferencia establecida y el factor de distinción utilizado. En definitiva, a modo de evaluación general, es posible afirmar que el test de racionalidad es marcadamente deferente ${ }^{57}$.

La noción general de igualdad también ha sido criticada por limitada, i.e., solo garantiza un trato igual, lo cual puede ser interpretado como una prohibición de cualquier forma de trato especial para los más desaventajados ${ }^{58}$. Si bien podría objetarse que esto se salvaría mediante la adecuada utilización de la segunda parte de la fórmula aristotélica, en los hechos existe una gran falta de elaboración acerca de cómo se debe tratar a los desiguales, i.e., en qué sentido y cuán diferente deben ser tratados ${ }^{59}$. Tampoco existe claridad respecto de cuáles serían las limitaciones al tratamiento jurídico diverso de los desiguales ${ }^{60}$, más allá de la idea aristotélica de "lo proporcional" ${ }^{1}$.

Otra crítica que se puede formular a la igualdad general es que sería completamente "relativa" o "relacional": mientras el trato sea el mismo, no sería relevante cuán bueno o malo es ${ }^{62}$. Más importante aún, la igualdad general sería insensible a las desigualdades de facto (sean preexistentes al trato diferenciador o consecuencias de aquel), siendo capaz de

\footnotetext{
56 Véase SADURSKI (2008) pp. 131 y ss.

57 Mccrudden y Prechal (2009) pp. 11 y ss.; Michelman (1986) pp. 26-27.

58 Peters (1999) pp. 75-77.

59 Adicionalmente, en algunos sistemas jurídicos se ha precisado que el trato desigual a los desiguales es solo permitido, pero no requerido. Véase, por ejemplo, los fallos del Consejo Constitucional Francés CC 79/107; 80/128; 87/232; 89/266; 91/290; 91/291; 92/316; 2007/557, y 2011/222. Algo similar puede apreciarse en las sentencias del Tribunal Constitucional Español STC 86/1985; 20/1986, y 16/1994.

60 Fredman (2001) p. 17.

61 Aristóteles (2009) Libro V. En Chile, véase Valdés (1992) p. 13.

62 Fredman (2001) p. 18
} 
generar solo obligaciones negativas ${ }^{63}$. Esto a su vez se relaciona con el cuestionamiento a la idea de "ceguera" o "neutralidad" de la ley, dando lugar a demandas que escapan a la igualdad general (e.g., discriminación positiva) ${ }^{64}$.

Finalmente, se ha argumentado que esta noción de igualad seguiría un modelo marcadamente individualista que la haría hostil a las ideas de igualdad grupal (de hecho, promovería la asimilación a los estándares mayoritarios) ${ }^{65}$.

\section{B. Igualdad como Protección de Bienes Públicos Importantes (Derechos Funda- mentales)}

Esta noción de igualdad constitucional se enfoca en la distribución de tipos especiales de bienes, tales como los derechos fundamentales ${ }^{66}$. La igualdad no se concibe entonces como un derecho autónomo, sino que se vincula a otros bienes o derechos, de forma que el objetivo no es proteger la igualdad en sí misma, sino la igualdad "de algo" o "en algo" 67 . Las desviaciones a este tipo de igualdad se sujetan normalmente a un escrutinio más estricto que la mera razonabilidad (e.g., la proporcionalidad europea o el "strict scrutiny" norteamericano), o al menos a una versión más exigente de este test.

La igualdad como protección de bienes importantes o derechos puede encontrarse en cláusulas constitucionales generales (e.g., igualdad en el ejercicio de los derechos fundamentales), o en provisiones asociadas a otros tantos bienes públicos o derechos específicos (e.g., igualdad en la participación política de miembros de partidos políticos e independientes).

Es importante destacar que esta concepción de igualdad no es incompatible con la noción de igualdad general o tradicional. En efecto, ellas comparten sus fundamentos (i.e., la idea de que existe una igualdad esencial entre individuos, y que las desviaciones a un trato igual deben ser justificadas). Sin embargo, creemos que en este segundo tipo de igualdad el bien o derecho asociado juega ciertos roles fundamentales. Es así como provee criterios para evaluar si un determinado trato debe considerarse como igual o desigual. Ello por cuanto los bienes o derechos en cuestión probablemente tendrán un núcleo y otros contenidos accesorios, y en tal caso solo la afectación del primero daría lugar a un tratamiento desigual rechazado por el ordenamiento jurídico. Así, por ejemplo, la igual protección de la libertad ambulatoria sería vulnerada si la autoridad detiene a uno de los participantes en una protesta que están realizando los mismos actos que el resto, y lo mantiene privado de libertad por un mes. Por el contrario, no existiría vulneración si los vecinos de solo una ca-

\footnotetext{
63 Fredman (2001) p. 18.

64 BECKer (1987) pp. 209 y ss.

65 Véase Mccrudden (2001) pp. 253-255; Fredman (2001) pp. 16-17; Fiss (1976) pp. 123 y ss.

66 Mccrudden y Prechal (2009) pp. 17 y ss.

${ }^{67}$ Esta visión de igualdad es común en el ámbito de los tratados internacionales (véase, por ejemplo, la Convención Europea de Derechos Humanos y la Convención Interamericana contra Toda Forma de Discriminación e Intolerancia). También se habría utilizado, por ejemplo, en la famosa primera sentencia del Consejo Constitucional Francés sobre las cuotas electorales para mujeres, donde estas fueron rechazadas -solo aparentemente en nuestra opinión- por violar la igualdad en el ejercicio de los derechos de voto y de ser candidato, los cuales habrían sido "conferidos" en "términos idénticos" para todos. Véase CC 82/146.
} 
lle dentro de un barrio no pueden utilizarla por unos minutos debido a su uso reservado a autoridades públicas. En otras palabras, la pregunta acerca de si la diferencia en cuestión es suficientemente relevante para el derecho como para constituir un tratamiento desigual es resuelta desde la perspectiva del derecho asociado.

Otra función del bien o derecho asociado es ayudar en la determinación del nivel o exigencia del escrutinio que se aplica a las desviaciones. En términos generales, a mayor importancia del bien o derecho, más exigente el examen. Adicionalmente, el bien o derecho asociado permite restringir las características personales que pueden utilizarse legítimamente para distinguir entre personas. Así, por ejemplo, la igualdad en el derecho al voto puede permitir condicionamientos por edad, criterio que no es aplicable a la igualdad en el derecho a la vida. Cabe también considerar que, dependiendo de si el bien o derecho en cuestión se concibe de manera formalista o substancial, la segunda noción de igualdad puede ir más allá de la mera igualdad formal, acercándose a una igualdad más bien material.

Finalmente, es importante destacar que esta clase de igualdad, aunque no es incompatible con la exigencia de obligaciones o deberes positivos ${ }^{68}$, es en principio contraria a tratamientos especiales o más favorables para grupos desaventajados. Asimismo, esta noción de igualdad mantiene un ethos más bien individualista, donde la igualdad de algo es normalmente concebida como igualdad de derecho individual.

\section{Igualdad como no discriminación por factores asociados a la pertenencia a ciertos grupos}

Esta noción de igualdad constitucional prohíbe hacer distinciones basadas en características o factores que definen la pertenencia a ciertos grupos (e.g., raza, sexo, religión) ${ }^{69}$. Desviaciones a esta clase de igualdad se someten a un escrutinio exigente, cuya severidad varía de acuerdo a las características específicas del factor que está en juego (por ejemplo, el uso de la raza es normalmente sujeto a un escrutinio más estricto que el uso de la edad), y también a través del tiempo. Siguiendo a $\mathrm{McCrudden}^{70}$, esta clase de igualdad sirvió de marco para el desarrollo de las doctrinas de la discriminación directa e indirecta (explicadas previamente), en cuanto elaboraciones más sofisticadas de la fórmula aristotélica de tratar igual a los iguales y desigual a los desiguales (igualdad general). Del mismo modo, esta noción de la igualdad constitucional se habría apoyado en la segunda parte de aquella fórmula para desarrollar doctrinas especiales sobre el embarazo, las acomodaciones razonables de los discapacitados, y la discriminación positiva, entendida como "las medidas que intentan incrementar la participación de ciertos grupos definidos en razón de factores tales como la raza, el género o la discapacidad, en aquellos contextos en los cuales se considera que tales grupos están subrepresentados"71.

La idea fundamental detrás de esta tercera noción de igualdad constitucional es la protección de grupos desaventajados, impidiendo así la existencia de "castas" o ciudadanos

\footnotetext{
68 Véase Feldman (2002) p. 143, refiriéndose a la jurisprudencia de la Corte Europea de Derechos Humanos.

69 Mccrudden y Prechal (2009) pp. 23 y ss. Véase también Michelman (1986) pp. 27 y ss.

70 Mccrudden y Prechal (2009) pp. 28 y ss.

71 Mccrudden y Prechal (2009) p. 38.
} 
de "segunda clase"72. Existe una preocupación especial sobre el daño sufrido por aquellos que son estigmatizados por su pertenencia a ciertos grupos ${ }^{73}$. En consecuencia, esta noción de igualdad no rechaza necesariamente todas las distinciones basadas en factores o "categorías sospechosas", sino solo aquellas que refuerzan la vulnerabilidad de los grupos desaventajados, con el consiguiente daño para la dignidad de sus miembros ${ }^{74}$. De esta forma, un trato preferencial basado en categorías sospechosas que es beneficioso para grupos desaventajados podría ser sometido a un escrutinio menos exigente, por cuanto ayudaría a que los "grupos inferiores" sean menos "casta" y además no causaría estigma a los "grupos superiores" $"$. En otras palabras, esta noción de igualdad constitucional propone un escrutinio de las desigualdades focalizado en fines y objetivos ${ }^{76}$, i.e., si las desigualdades refuerzan o debilitan el estatus de casta de un grupo; si aquellas estigmatizan o no ${ }^{77}$; cómo la superación del estatus de casta de un grupo "compite" o se armoniza con otros intereses legítimos que podrían justificar la desigualdad no obstante sus efectos reforzadores o creadores de una casta $^{78}$, etc. Siguiendo esta lógica centrada en los fines, la estrictez del escrutinio está dada por la naturaleza del fin u objetivo perseguido por la medida desigual ${ }^{79}$. En suma, es posible apreciar un importante contraste con la primera noción de igualdad constitucional (igualdad general), la cual no se focaliza en fines, sino que en los medios para alcanzar aquellos y en la relación entre tales medios y fines.

En razón de lo anterior, es posible afirmar que esta tercera noción de igualdad ha avanzado bastante en el proceso de dar contenido al "vacío" de la igualdad general, no solo por cuanto tiende a excluir ciertos criterios de comparación (i.e., categorías sospechosas), sino principalmente porque entrega un criterio substancial específico para evaluar las desigualdades: su impacto sobre el desarrollo y/o perpetuación de las situaciones de casta o de estigmatización de grupos.

Ahora bien, un elemento clave de esta noción de igualdad es la idea de grupo, la que, sin embargo, es altamente problemática por una serie de razones. En primer lugar, no existe acuerdo respecto de qué constituye un grupo. Ciertamente es más que una mera colección o universalidad de individuos, pero la definición de ese "más" da lugar a un listado de factores controversiales. Ejemplos de ellos son la identificación que tengan los miembros con el grupo; la interdependencia entre tales miembros; la estabilidad del grupo en el tiempo; la inmutabilidad de la pertenencia al grupo; el reconocimiento del grupo como algo distinto de sus miembros, etc. ${ }^{80}$. Lo anterior se vuelve aún más complejo debido a que todos los

\footnotetext{
72 Véase Sunstein (1994) pp. 2428 y ss.; Fiss (1976) pp. 147-156; Michelman (1976) pp. 27-28; Peters (1999) pp. 79-81.

73 BRest (1976) pp. 48 y ss.; Fiss (1976) pp. 157 y ss.; SUNSTEIN (1994) pp. 2428-2433.

74 Véase RÉAume (2003) p. 676, quien afirma que la determinación de si existe daño a la dignidad es una pregunta normativa que no depende de los efectos materiales o sicológicos concretos sobre las víctimas.

75 Véase Brest (1976) pp. 16 y ss.; Sunstein (1994) pp. 2439 y ss. y 2452.

76 Fiss (1976) p. 153.

77 Sunstein (1994) p. 2429; Brest (1976) pp. 16 y ss.. Véase también SAdurSKi (2008) pp. 140-142.

78 FISS (1976) pp. 165 y ss.; BREST (1976) p. 15.

79 Fiss (1976) p. 153.

${ }^{80}$ Véase Fiss (1976) pp. 148-149.
} 
factores mencionados admiten graduación, i.e., más que su presencia o ausencia, lo importante es la intensidad con que se manifiestan en un caso concreto.

En segundo término, el concepto de grupo se relaciona negativamente con el "esencialismo", i.e., asumir que cada grupo tiene "esencias fijas y dadas de una vez y para siempre, con características que están distribuidas homogéneamente entre los miembros del grupo" ${ }^{\prime 1}$. El esencialismo es generalmente rechazado como una forma de determinismo social o biológico, y como una peligrosa y falsa simplificación que niega la autonomía personal, la pluralidad de identidades, y la diversidad dentro de cada grupo ${ }^{82}$.

En tercer lugar, surge el problema de identificar qué grupos (y consecuentemente, qué características personales), debieran gozar de una protección constitucional especial. Si bien esta discusión excede el marco de este trabajo, cabe mencionar aquí que no todos los grupos tienen demandas o "títulos" igualmente sólidos. Algunos factores a considerar son la penetración e intensidad de la discriminación; el daño sufrido por el grupo; la persistencia de la discriminación en el tiempo; la fluidez o rigidez de la pertenencia al grupo, la utilidad social general, entre otros ${ }^{83}$. A nivel comparado, nos parece que los ejemplos más comunes son las mujeres, ciertas razas o etnias, y los discapacitados.

En cuarto término, existe un problema adicional vinculado a la discriminación múltiple o multidiscriminación, la que se produce cuando una persona pertenece simultáneamente a varios grupos desaventajados. La igualdad constitucional tratada en esta sección puede no responder adecuadamente a tales individuos, ya que inspiraría medidas que si bien beneficiarían a alguno(s) de esos grupos, podrían a la vez perjudicar a otros. También es posible que tales medidas beneficien a un grupo como un todo (los diaguitas), pero no a una sección dentro del mismo que sufre de un tipo adicional de discriminación (e.g., las mujeres diaguitas). En términos más generales, es probable que tales medidas no sean capaces de hacerse cargo de la complejidad única de las situaciones sujetas a multidiscriminación ${ }^{84}$.

Desde una perspectiva formal, la tercera noción de igualdad constitucional se asocia a cláusulas específicas que enuncian categorías "sospechosas". Nos remitimos en esta materia a lo señalado en la sección III.2 precedente, en particular en relación a los problemas interpretativos causados por estas cláusulas (eventual expansión de los criterios sospechosos y relación con las cláusulas generales de igualdad). Cabe reiterar, sin embargo, que en términos prácticos, estas cláusulas impulsan a los jueces a ser más estrictos con las desviaciones a la igualdad constitucional.

Finalmente, pudiera parecer que esta tercera noción de igualdad constitucional contrasta con las dos primeras en cuanto se centraría en grupos, dejando de lado al individuo. Creemos, sin embargo, que esta es solo una de las interpretaciones posibles ${ }^{85}$. En efecto,

81 Gould (1996) p. 182. Traducción propia.

82 Véase Williams (1998) p. 6; Gould (1996) pp. 182-183; Young (2000) pp. 82-91; Mansbridge (1999) pp. 637-639.

83 Véase Brest (1976) p. 11; Fiss (1976) p. 150.

84 Existe una interesante literatura comparada sobre el fenómeno de la multidiscriminación, tales como CRENSHaW (1989); García (2007); Jordan-ZaChery (2007); Simien (2007).

85 Véase Michelman (1986) pp. 28-32. 
si bien esta concepción de igualdad es ininteligible sin la noción de grupo, y reflejaría un "modelo de justicia grupal fuerte" ${ }^{86}$, aquella también puede leerse desde una perspectiva más centrada en el individuo ${ }^{87}$. De este modo, es posible hacer hincapié en que la víctima de la discriminación y del estigma no es el grupo como tal, sino que sus miembros individuales; que la erradicación de castas es necesaria para el desarrollo pleno de sus miembros, y que la no discriminación en base a categorías sospechosas es un derecho individual garantizado por los tribunales de justicia ${ }^{88}$. Reconocemos, sin embargo, que en general esta concepción de igualdad denota una tendencia a enfocarse en los grupos.

\section{La igualdad como obligación positiva de promover la igualdad de oportunidades (y de facto)}

Esta noción de la igualdad constitucional requiere la promoción activa de la igualdad de oportunidades - y eventualmente de la igualad de facto- de ciertos grupos desaventaja$\operatorname{dos}^{89}$. En términos formales, esta igualdad se sustenta en cláusulas constitucionales que utilizan ciertas expresiones o palabras tales como "igualdad substantiva", "igualdad de oportunidades", "promoción de la igualdad", "igualdad de facto", o similares.

Si bien la igualdad de oportunidades es un término altamente confuso ("un caos intelectual y moral” que, según algunos, debería ser abandonado como concepto ${ }^{90}$ ), postulamos que es posible reconocer en ella dos componentes fundamentales. El primero es la idea de carreras o puestos abiertos a los talentos ${ }^{11}$, mientras que el segundo consiste en la remoción de al menos algunos de los obstáculos relevantes que enfrentan los individuos que persiguen los mismos objetivos ${ }^{92}$.

La idea de carreras o puestos abiertos al talento es, en términos cronológicos, el primer elemento en surgir ${ }^{93}$, y está íntimamente unido a las nociones de mérito y meritocracia $^{94}$. De este modo, se afirma que dado el limitado número de "buenas posiciones", aquellas deben ser asignadas a los mejores calificados para las mismas ${ }^{95}$. En otras palabras, las posibilidades de obtener dichas posiciones deben depender del talento o mérito individual, y no factores tales como la estratificación social, el nepotismo o el capricho.

La noción de mérito, sin embargo, presenta una serie de dificultades, comenzando por el hecho de que definir qué debe entenderse por mérito es algo sumamente controver-

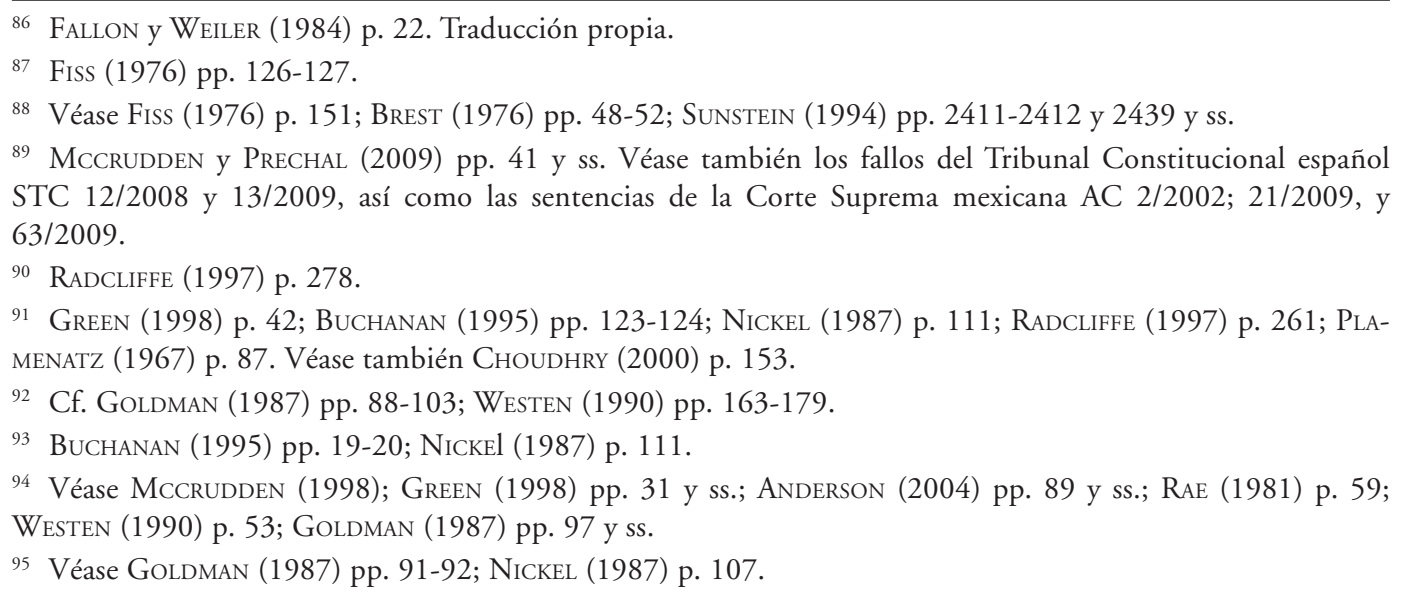


sial (e.g., habilidades genéticas o adquiridas; conocimiento; experiencia; atributos físicos o psicológicos; logros; virtudes $)^{96}$. En realidad, el mérito es una noción altamente contextualizada, i.e., su definición depende en gran medida de las circunstancias donde es invocado, particularmente la naturaleza de la posición o el bien deseado ${ }^{97}$. Un problema adicional es la dificultad de medir y comparar méritos (incluso cuando existe algún tipo de "test objetivo", situación que no es la regla general, aquellos son rutinariamente acusados de falta de imparcialidad real, ya que reforzarían patrones establecidos de desigualdad y exclusión), lo que a su vez nos lleva al controversial tópico de la justicia procedimental en la determinación y evaluación del mérito ${ }^{98}$. Y para mayor dificultad, se ha destacado que la meritocracia puede no ser especialmente igualitaria o redistributiva ${ }^{99}$. En efecto, los méritos se encuentran distribuidos desigualmente en la población. Más aún, no todos los talentos son apreciados como tales, sino que cada sociedad valora solo una cantidad limitada de ellos. En consecuencia, considerar la igualdad de oportunidades exclusivamente como meritocracia sería una doctrina fuertemente conservadora del statu quo, capaz de reforzar los patrones de desigualdad existentes en una sociedad ${ }^{100}$.

El segundo elemento de la igualdad de oportunidades asume la premisa de que los individuos persiguen múltiples objetivos, y que en sus caminos o actividades para lograrlos se enfrentan a diversos obstáculos. La igualdad de oportunidades requiere que los individuos que persiguen el mismo objetivo enfrenten los mismos obstáculos relevantes para conseguirlo. En consecuencia, obstáculos que solo afectan a uno o a algunos (pero no a todos) de los agentes en cuestión, deben ser removidos ${ }^{101}$.

Además de los dos elementos fundamentales antes mencionados, se ha argumentado que la igualdad de oportunidades comprendería otros muy disímiles y variados, dando lugar a diversas nociones de la misma ${ }^{102}$. Es imposible extenderse acerca de las características y diferencias de todas estas nociones, pero es importante destacar que la igualdad de oportunidades (incluso comprendiendo solo los dos elementos centrales antes explicados), puede comprender mucho o muy poco, dependiendo de la perspectiva ideológica y filosófica que se adopte. Es así como puede variar desde algo similar a la visión de no intervención o "dejar hacer" del liberalismo clásico, a una exigencia de gran intervención estatal para igualar oportunidades lato sensu, más propia del igualitarismo contemporáneo. En términos más específicos, la pregunta esencial es cuán lejos debe ir la igualación de oportunidades. Este tema es delicado, porque demuestra que la igualdad de oportunidades puede convertirse en una "pendiente resbaladiza" que comienza en la igualdad formal y termina en la

\footnotetext{
96 Véase Mccrudden (1998) pp. 543-579; Green (1998) pp. 31-40.

97 Así, por ejemplo, en el ámbito laboral se ha afirmado que los méritos deben ser relevantes para el trabajo en cuestión. Véase FishKin (1987) pp. 35-36.

98 Véase Fishkin (1987) p. 35; Bergmann (1996) pp. 102 y ss.

99 SCHAAR (1967) p. 230.

100 Véase SchaAR (1967) p. 230; Kendrigan (1984) pp. 71 y ss.

101 Véase Westen (1990) pp. 163 y ss.; Puyol (2001) p. 118; Goldman (1987) p. 102; Nickel (1987) p. 110.

102 Ejemplos en Nickel (1987) p. 111; SChaAr (1967) p. 229; Fishkin (1987) pp. 36-37; Green (1998) pp. 42 y 104; Buchanan (1995) pp. 121-123 y ss.; Choudhry (2000) p. 153. Véase también la ilustrativa obra de RADCLIFFE (1997) pp. 253-279.
} 
igualdad de resultados ${ }^{103}$. Al respecto, debe destacarse que, como regla general, mientras más intensa o demandante sea la versión de igualad oportunidades que se persigue, mayor será la intervención estatal en la vida privada y familiar requerida para igualar más y más aspectos. Llevado al extremo, esto requeriría la destrucción de bienes jurídicos tan fundamentales como la familia, la meritocracia, la libertad de enseñanza, e incluso la libertad, identidad y dignidad de la persona ${ }^{104}$.

Un posible marco para medir las diferentes "intensidades" de las distintas visiones acerca de la igualdad de oportunidades se basa en la dicotomía entre desigualdades biológicas/naturales y desigualdades sociales (véase sección III.1 precedente). Una aproximación más "liberal" propondría la erradicación de diferencias sociales en la medida que aquellas constituyan un obstáculo insuperable para una competencia justa (e.g., acceso a la educación para las mujeres en países donde están excluidas o francamente limitadas a este respecto). Otras diferencias sociales, sin embargo, podrían justificarse en base a diversos argumentos (e.g., incentivos correctos, libertad, utilidad social). Visiones más ambiciosas de la igualdad de oportunidades irían incrementando gradualmente aquellas diferencias sociales a ser erradicadas, si bien la abolición de todas ellas sería siempre algo implausible y no deseable ${ }^{105}$. Alternativas más extremas comprenderían las desigualdades biológicas: no su erradicación (muchas veces imposible y no necesariamente deseable ${ }^{106}$ ), sino que su compensación mediante una distribución diferenciada de bienes sociales. El argumento central en este caso sería que las diferencias biológicas son tan inmerecidas como las diferencias sociales $^{107}$, y que si solo se corrigieran las últimas, surgiría una suerte de "aristocracia natural" tan o más desigual que la "aristocracia social". El problema de estas visiones, sin embargo, es que asumen que las diferencias biológicas pueden ser medidas, agregadas y compensadas por diferencias sociales, supuestos sumamente cuestionables.

Una aproximación complementaria es la que distingue entre la igualdad de oportunidades centrada en las probabilidades - proveer la misma probabilidad de obtener algo- y aquella focalizada en los medios - poner a disposición los mismos instrumentos para obtener algo- (véase la sección II.2.b precedente). La primera es muy exigente, ya que requeriría la completa eliminación o compensación de las desigualdades naturales y sociales para que "nada acerca de las personas afecte el resultado" ${ }^{108}$. La segunda es una opción más pragmática, pero a la vez inherentemente limitada en sus resultados dada la distribución desigual de los talentos y el hecho que una completa igualdad de medios es imposible de $\log \operatorname{rar}^{109}$.

\footnotetext{
103 Radcliffe (1997) p. 255; Sadurski (2006) p. 3.2; Facio y Morgan (2009) p. 1147. Véase también el voto de minoría en el fallo del Tribunal Constitucional español 12/2008, sobre la constitucionalidad de las coutas electorales por sexo.

104 Véase RaE (1981) pp. 75-76; BUCHANAN (1995) pp. 125-127 y 132 ss.; FiShKIN (1987) pp. 401-404; LLOYDThomas (1977) pp. 401-404; Gross (1987) pp. 121-142; Goldman (1987) pp. 96-97; SCHAAR (1967) pp. $238-239$.

105 Goldman (1987) p. 92; Bedau (1967) pp. 13-15 y 26.

106 Goldman (1987) pp. 91-92. Véase también la obra de Buchanan (1995) pp. 105-135.

107 Goldman (1987) p. 98.

108 RaE (1981) p. 66. Traducción propia. Ver también Goldman (1987) p. 100.

109 Gross (1987) p. 128.
} 
Ahora bien, parte importante de la discusión acerca del contenido de la igualdad de oportunidades pareciera vincularse a formas distintas de entender lo que es una oportunidad. En efecto, existen diversas visiones que van de lo más general (e.g. "la capacidad de hacer que nuestras vidas tomen el rumbo que deseamos"110) a algo relativamente más acotado (e.g., el derecho a una competencia justa ${ }^{111}$ ). Otras aproximaciones apelan al sentido común (e.g., "no es una garantía ni tampoco una posibilidad remota de alcanzar un objetivo"112), o son claramente pragmáticas (e.g., algo que está más cerca de una posibilidad material que un mero derecho $\left.{ }^{113}\right)$. Esta confusión conceptual es agravada por varias complicaciones. En primer lugar, en ocasiones se asume que las oportunidades son valoradas porque ellas nos permiten alcanzar un objetivo, pero también es posible considerarlas como un bien en sí mismas, cambiando así el foco desde los objetivos a los medios o recursos ${ }^{114}$. En segundo término, es debatible si la igualdad de oportunidades requiere proveer a todos las mismas oportunidades, o más bien oportunidades "igualmente buenas" (asumiendo que sea posible medir y comparar esto en forma objetiva ${ }^{115}$. En tercer lugar, las oportunidades pueden ser consideradas como bienes escasos sujetos a competencia, o como un mínimo a ser garantizado a todos ${ }^{116}$.

En conclusión, es posible afirmar que la igualdad de oportunidades, siendo un concepto muy atractivo, presenta importantes dificultades. En primer lugar, es singularmente ambigua $^{117}$ (lo que puede ser una de las razones de su gran atractivo y poder retórico) ${ }^{118}$. En segundo término, aquella tiende a entrar en conflicto con otros bienes jurídicos: mientras una noción débil de la igualdad de oportunidades es compatible con altos grados de desigualdad $^{119}$, sus versiones fuertes pueden ser irreconciliables con la libertad, la familia e incluso la identidad personal. En tercer lugar, la completa igualdad de oportunidades es evidentemente utópica ${ }^{120}$. Finalmente, aquella es generalmente vista como una noción individualista, debido a que los talentos, obstáculos, justa competencia, discriminación, etc., son todos considerados desde la perspectiva del individuo ${ }^{121}$.

En el contexto de la cuarta noción de igualdad constitucional, al menos algunas de las dificultades antes mencionadas son abordadas al enfatizar la idea de igualdad de facto ${ }^{122}$.

\footnotetext{
110 RadCliffe (1997) p. 274. Traducción propia.

111 Goldman (1987) p. 91; Lloyd-Thomas (1977) p. 392.

112 NiCKel (1987) p. 110. Traducción propia.

113 Lloyd-Thomas (1977) p. 392.

114 Véase RadCliffe (1997) pp. 271-273.

115 Lloyd-Thomas (1977) p. 389.

116 Ver Lloyd-Thomas (1977) pp. 390-392 y su noción de igualdad de oportunidades no competitiva.

117 WeSTEN (1990) pp. 174-175.

118 Véase Westen (1990) pp. 164 y 178-179.

119 Véase Lloyd-Thomas (1977), pp. 400-401; Westen (1990) pp. 176-177; Schaar (1967) pp. 231-238.

120 Véase Gross (1987) pp. 126-130; Lloyd-Thomas (1977) p. 392; Goldman (1987) p. 102.

121 Véase, SchaAr (1967) p. 247; Lacey (1987) p. 410.

122 Cabe destacar que si bien existe una conexión entre igualad de facto e igualdad sustancial, no se ha utilizado este último término debido a la gran confusión existente sobre su contenido y significado, lo que no significa que no tengo aplicación constitucional. Véase, por ejemplo, las sentencias del Tribunal Constitucional español 216/1991 y 269/1994.
} 
Como mencionábamos previamente, la igualdad general es comúnmente acusada de "formal", siendo indiferente a la existencia de desigualdades en la "vida real" (en efecto, la igualdad formal puede aumentar o disminuir las desigualdades reales ${ }^{123}$ ). Por tanto, aquella es complementada por una noción de igualdad que: i) considere las diferencias fácticas de las personas, y/o ii) otorgue un trato diferente para asegurar una igualdad "real" (i.e., en las condiciones concretas de vida de las personas $\left.{ }^{124}\right)$. En consecuencia, esta cuarta noción de igualdad constitucional asume una igualdad de oportunidades ambiciosa, al punto de poder confundirse, al menos parcialmente, con una igualdad de resultados en cuanto es capaz de transformar efectivamente la realidad.

La igualdad fáctica, sin embargo, presenta sus propios problemas. Es así como siendo una noción de textura abierta, puede significar cosas muy distintas y ser evaluada de acuerdo a estándares muy diversos ${ }^{125}$. Más aún, su eventual foco en las consecuencias de los actos y políticas de igualdad la convierte en un criterio altamente especulativo a la hora de diseñar aquellas. Esto se agrava al considerar que la determinación, medición y evaluación de los efectos las políticas de igualdad suele ser altamente controversial. Adicionalmente, cuando la igualdad fáctica es utilizada para justificar una desviación de la igualdad general, deja de estar cubierta por la presunción en favor de la igualdad ${ }^{126}$. En otras palabras, el trato diverso impuesto por la igualdad de facto debe justificarse, y sus fundamentos probarse.

\section{CONCLUSIONES}

1. La igualdad es un concepto complejo, superlativamente equívoco, y carente de contenido propio más allá de lo meramente relacional (comparación de dos entidades diferentes de acuerdo a un estándar común), por lo cual requiere de "metaprincipios" que le otorguen un contenido sustancial, tales como la dignidad o la justicia.

2. El ordenamiento constitucional recepciona la igualdad y le imprime un carácter particular. La igualdad entre individuos se convierte en la regla general, y se enfatiza el combate a la discriminación arbitraria, restringiendo la libertad del agente comparador en la selección del estándar de comparación, su propósito, y la relación entre ambos. La vacuidad de la igualdad se resuelve apelando a metaprincipios contextualizables en el orden sistemático de valores y principios contenidos en la constitución. 3. La igualdad constitucional varía entre ordenamientos jurídicos, tanto en lo formal como en su contenido. Algunas variaciones formales en las cláusulas constitucionales pueden incidir en el significado sustantivo otorgado a la igualdad, tales como la identificación del obligado por el mandato constitucional; la manera de vincular la igualdad y la ley; su generalidad o especialidad; el uso de adjetivos calificativos de la igualdad (e.g., "real"; "de oportunidades"), y la presentación de la igualdad como valor/principio y/o como derecho individual.

\footnotetext{
123 Green (1998) p. 43.

124 Véase Alexy (2002) pp. 276 y ss.

125 Véase Alexy (2002) p. 282.

126 Alexy (2002) p. 283. Contrastar con Sadurski (2008) pp. 108 y ss.
} 
4. Existen diferentes nociones sustantivas de la igualdad constitucional: la general o tradicional; como protección de bienes públicos importantes (derechos fundamentales); como no discriminación por factores asociados a la pertenencia a ciertos grupos, y como obligación positiva de promover la igualdad de oportunidades (y de facto). Estas nociones pueden superponerse e incluso entrar en conflicto.

5. La igualdad general, tributaria de la fórmula aristotélica de tratar igual a los iguales y desigual a los desiguales, ha servido de base para las demás nociones de igualdad, las que surgen, al menos en parte, como respuesta a los problemas de la igualdad general. Algunos de ellos ya parecen superados (e.g., confusión con la generalidad, abstracción y neutralidad de le ley), mientras que otros mantienen su vigencia (e.g., baja exigencia del test de racionalidad; formalidad que impide considerar las desigualdades fácticas; falta de elaboración de la segunda parte de la fórmula aristotélica; excesivo individualismo).

6. La igualdad como protección de bienes públicos importantes (derechos fundamentales), sacrifica la autonomía de la igualdad, la que se convierte en accesoria de otro derecho fundamental. Este derecho determina materias tales como el nivel de escrutinio a que se somete la diferencia de trato; la formalidad o sustancialidad de la igualdad asociada al derecho en cuestión, etc. Esta noción de igualdad se centra en el individuo y sus derechos, siendo más bien reticente a la igualdad entre grupos.

7. La igualdad como no discriminación por factores asociados a la pertenencia a ciertos grupos se traduce en la consagración de "categorías sospechosas" tales como la raza y el sexo, las que no deben utilizarse como factor de diferenciación salvo que se ofrezcan muy buenas razones para ello. Su finalidad esencial es impedir o desmantelar la existencia de "castas", así como la estigmatización social de sus miembros. Por lo mismo, diferencias que benefician a grupos desaventajados quedarían sujetas a un control menos exigente. Si bien el elemento individualista subsiste, existe mayor énfasis en el grupo.

8. La igualdad como obligación positiva de promover la igualdad de oportunidades y de facto, varía en su contenido según las nociones más o menos ambiciosas que exista de aquellas. En todo caso, se enfatiza el mérito, la remoción de los obstáculos que afectan el desarrollo de solo algunas personas (normalmente las más desaventajadas), y la consideración de las condiciones reales de vida de los individuos.

9. La pluralidad de significados de la igualdad constitucional obliga a deconstruir las demandas de igualdad, de forma de identificar el tipo de igualdad que asumen, y analizar los posibles conflictos con otras nociones de igualdad recogidas por el sistema constitucional.

\section{BIBLIOGRAFÍA CITADA}

Abram, Morris (1986): "Affirmative Action: Fair Shakers and Social Engineers", Harvard Law Review, vol. 99: pp. 1312-1326.

AleXander, Larry (1992): "What Makes Wrongful Discrimination Wrong? Biases, Preferences, Stereotypes, and Proxies' “, University of Pennsylvania Law Review, vol. 141: pp. 149-219. 
Alexy, Robert (2002): A Theory of Constitucional (New York, Oxford University Press). Anderson, Terry (2004): The Pursuit of Fairness (New York, Oxford University Press). Aristóteles (2009): Ética a Nicómaco (Madrid, Tecnos).

Atria, Fernando (1997): Los Peligros de la Constitución. La Idea de Igualdad en la Jurisdicción Nacional (Santiago, Escuela de Derecho Universidad Diego Portales).

Becker, Mary E (1987): "Prince Charming: Abstract Equality", The Supreme Court Review, pp. 201-247.

Bedau, Hugo Adam (1967): "Egalitarism and the Idea of Equality" en Pennock, Roland y Chapman, John (edit.) Equality (New York, Atherton Press) pp. 3-27.

Bergmann, Barbara (1996): In Defense of Affirmative Action (New York, Basic Books).

Brest, Paul (1976): "In Defense of the Antidiscrimination Principle", Harvard Law Review, vol. $90 \mathrm{~N}^{\circ} 1$ : pp. 1-54.

Browne, Derek (1978): "Nonegalitarian Justice", Autralasian Journal of Philosophy, vol. 56 $\mathrm{N}^{\circ}$ 1: pp. 48-60.

Buchanan, Allen (1995): "Equal Opportunity and Genetic Intervention”, Social Philosophy and Policy Foundation, vol. $12 \mathrm{~N}^{\circ}$ 2: pp. 105-135.

Bulnes, Luz (2009): La Igualdad Ante la Ley y la Evolución de la Jurisprudencia del Tribunal Constitucional (Santiago, Editorial Jurídica de Chile).

Buchanan, Allen (1995): "Equal Opportunity and Genetic Intervention", Social Philosophy and Policy Foundation, vol. $12 \mathrm{~N}^{\circ}$ 2: pp. 105-135.

CEA, José Luis (2012): Derecho Constitucional Chileno (Santiago, Ediciones UC, segunda edición).

Choudhry, Sujit (2000): “Distribution vs. Recognition: The Case of Anti-Discrimination Laws”, George Mason Law Review, vol. 9: pp. 145-178.

Correa, Jorge (2011): Jurisprudencia del Tribunal Constitucional en materia de Igualdad Ante la Ley ¿Saliendo de la Pura Tautología? (Anuario de Derecho Público, Ediciones Universidad Diego Portales).

Covarrubias, Ignacio (2012): "La Desproporción del Test de Proporcionalidad: Aspectos Problemáticos en su Formulación y Aplicación”, Revista Chilena de Derecho, vol. 39 $\mathrm{N}^{\circ}$ 2: pp. 447-480.

Covarrubias, Ignacio (2013): “¿Puede la dignidad humana ser un principio comúnmente compartido en materia de adjudicación constitucional? Actualidad Jurídica, vol. 15 No 29: pp. 147-165.

CrenshaW, Kimberle (1989): "Demarginalizing the Intersection of Race and Sex: A Black Feminist Critique of Antidiscrimination Doctrine, Feminist Theory and Antiracist Politics", University of Chicago Legal Forum, pp. 139-167.

Díaz de Valdés, José Manuel (2013): “¿Es la Ley Zamudio Verdaderamente una Ley General Antidiscriminación?”, Actualidad Jurídica, vol. $14 \mathrm{~N}^{\circ}$ 28: pp. 279-297.

Eastland, Terry (1997): Ending Affirmative Action. The Case of Colorblind Justice (New York, BasicBooks).

Enders, Christoph (2010): "A Right to Have Rights - The German Constitutional Concept of Human Dignity", NUJS Law Review, vol. 3 N³: pp. 253-264. 
Espejo, Nicolás (2000): La Garantía de la No Discriminación y el Principio de Igualdad (Santiago, Escuela de Derecho Universidad Diego Portales).

Facio, Alda y Morgan, Martha (2009): "Equity or Equality for Women? Understanding CEDAW's Equality Principles”, Alabama Law Review, vol. 60 № 5: pp. 1133-1147.

Fallon, Richard y Weiler, Paul (1984): "Firefighters v. Stotts: Conflicting Models of Racial Justice", The Supreme Court Review, pp. 1-68.

Feldman, David (2002): Civil Liberties and Human Rights in England and Wales (Oxford, Oxford University Press, segunda edición).

Ferrajoli, Luigy (2010): Derechos y Garantías. La Ley del más débil (Madrid, Trotta, séptima edición).

Fernández, Miguel Ángel (2004): Principio Constitucional de la Igualdad Ante la Ley (Santiago, LexisNexis).

Fredman, Sandra (2008): Human Rights Transformed (Oxford, Oxford University Press).

Figueroa, Rodolfo (2000): Igualdad y Discriminación. Igualdad, Libertad de Expresión e Interés Público (Santiago, Escuela de Derecho Universidad Diego Portales).

FishKin, James (1987): "Liberty Versys Equal Opportunities” en Paul, Ellen (edit.) Equal Opportunity (Oxford, Basil Blackwell) pp. 32-48.

Fiss, Owen M (1976): "Groups and the Equal Protection Clause", Philosophy and Public Affairs, vol. 5: pp. 107-177.

Fredman, Sandra (2001): “Combating Racism with Human Rights: The Right to Equality" en Fredman, Sara (edit.) Discrimination and Human Rights. The case of Racism (Oxford, Oxford University Press) pp. 9-44.

GarCía, Lisa (2007): “Intersections of Inequality: Understanding Marginalization and Privilege in the Post-Civil Rights Era”, Politics and Gender, vol. 3 N²: pp. 232-248.

GARDNER, John (1989): "Liberals and Unlawful Discrimination", Oxford Journal of Legal Studies, vol. 9: p. 1.

Goldman, Alan (1987): “The Justification of Equal Opportunity" en Paul, Ellen (edit.) Equal Opportunity (Oxford, Basil Blackwell) pp. 88-103.

Gould, Carol (1996): "Diversity and Democracy: Representing Differences" en Benhabib, Seyla (edit.) Democracy and Differences (Princeton, Princeton University Press) pp. 171-186.

Grant, Evadné (2007): “Dignity and Equality", Human Rights Law Review, vol. 7 № 2: pp. 299-329.

Green, Phillip (1998): Equality and Dremocracy (New York, New Press).

Kendrigan, Mary Lou (1984): Political Equality in a Democratic Society (Westport, Greenwood Press).

Gross, Barry (1987): “Real Equal Opportunity” en Paul, Ellen (edit.) Equal Opportunity (Oxford, Basil Blackwell).

Huscroft, Grant (2000): "Discrimination, Dignity, and the Limits of Equality", Otago Law Review, vol. 9 No 4: pp. 697-712.

Jordan-Zachery, Julia S (2007): "Am I a Black Woman or a Woman Who is Black? A Few Thoughts on the Meanings of Intersectionality", Politics and Gender, vol. 3 N ${ }^{\circ}$ 2: pp. 254-263. 
LaCey, Nicola (1987): "Legislation Against Sex Discrimination: Questions from a Feminist Perspective", Journal of Law and Society, vol. 14: pp. 411-421.

Lloyd-Thomas, David (1977): "Competitive Equality of Opportunity", Mind, vol. LXXXVI No 343: pp. 388-404.

Loury, Glenn C (1987): "Why Should We Care About Group Inequality?”, Social Philosophy and Policy, vol. $5 \mathrm{~N}^{\circ} 1$ : pp. 249-271.

Mansbridge, Jane (1999): "Should Blacks Represent Blacks and Women Represent Women? A Contingent "Yes"”, The Journal of Politics, vol. 61 N 61: pp. 628-657.

Martínez, Ramón (2000): Igualdad y Razonabilidad en la Justicia Constitucional Española (Almería, Universidad de Almería).

MCCRISTAL, Jerome (1994): "Color Blind Remedies And The Intersectionality Of Opresión: Policy Arguments Masquerading As Moral Claims”, New York University Law Review, vol. 69: pp. 162-196.

McCrudden, Christopher (1998): "Merit Principles", Oxford Journal of Legal Studies, vol. $18 \mathrm{~N}^{\circ}$ 4: pp. 543-579.

McCrudden, Christopher (2008): "Human Dignity and Judicial Interpretation of Human Rights", European Journal of International Law, vol. 19 N 5: pp. 655-724.

McCrudden, Christopher (1994): Equality in Law between Men and Women in the European Community (London, Martinus Nijhoff).

McCrudden, Chistopher (2004): "Introduction" en McCrudden, Christopher (edit.) AntiDiscrimination Law (Aldershot, Ashgate) pp. xi-xxxii.

McCrudden, Christopher (2001): "International and European Norms Regarding National Legal Remedies for Racial Inequality” en Fredman, Sara (edit.) Discrimination and Human Rights. The case of Racism (Oxford, Oxford University Press) pp. 251-307.

Michelman, Frank (1986): "The Meanings of Legal Equality", The BlackLetter Journal, pp. 24-36.

Nickel, James (1987): "Equal Opportunity in a Pluralistic Society" en Paul, Ellen (edit.) Equal Opportunity (Oxford, Basil Blackwell) pp. 104-119.

Nogueira, Humberto (1997): "El Derecho a la Igualdad en la Jurisprudencia Constitucional", Revista de Derecho de la Universidad Católica de Valparaíso, vol. XVIII: pp. 167-184.

Pérez Luño, Antonio Enrique(2007): Dimensiones de la Igualdad (Madrid, Editorial Dykinson, segunda edición).

Peters, Anne (1999): Women, Quotas and Constitutions: A Comparative Study of Affirmative Action under American, German, EC and International Law (London, Kluwer Law International).

Plamenatz, John (1967): "Diversity of Rights and Kinds of Equality" en Pennock, Roland y Chapman, John (edit.) Equality (New York, Atherton Press) pp. 79-98.

Pojman, Louis y Westmoreland, Robert (1997): Equality. Selected Readings (New York, Oxford University Press).

Post, Robert (2000): "Prejudicial Appearances: The Logic of American Antidiscrimination Law”, California Law Review, vol. 88: pp. 1-40.

Puyol, Ángel (2001): El Discurso de la Igualdad (Barcelona, Crítica).

RADCLIfFe, Janet (1997): "Equality of Opportunity”, Ration, vol. X N³: pp. 253-279. 
RaE, Douglas (1981): Equalities (Cambridge, Harvard University Press).

RaO, Neomi (2011): "Three Concepts of Dignity in Constitutional Law", Notre Dame Law Review, vol. $86 \mathrm{~N}^{\circ}$ 1: pp. 183-271.

Rawls, John (1999): A Theory of Justice (Oxford, Oxford University Press).

RÉAume, Denise G (2003): "Discrimination and Dignity”, Lousiana Law Review, vol. 63: pp. 645-695.

SADURSKI, Wojciech (2008): Equality and Legitimacy (Oxford, Oxford University Press).

SchaAR, John (1967): "Equality of Opportunity and Beyond" en Pennock, Roland y Chapman, John (edit.) Equality (New York, Atherton Press) pp. 228-249.

Simien, Evelyn (2007): "Doing Intersectionality Research: From Conceptual Issues to Practical Examples", Politics and Gender, vol. 3 N² 2: pp. 264-271.

Soberanes, José María (2011): La Igualdad y la Desigualdad Jurídicas (Ciudad de México, Porrúa).

Sowell, Thomas (2004): Affirmative Action Around the World (New Haven, Yale University Press).

STANLEY, Benn (1967): "Egalitarism and the Equal Consideration of Interests" en Pennock, Roland y Chapman, John (edit.) Equality (New York, Atherton Press) pp. 61-78.

Sunstein, Cass (1994): "The Anticaste Principle", Michigan Law Review, vol. 92: pp. 2410-2455.

Temkin, Larry (1986): "Inequality", Philosophy and Public Affairs, vol. 15 N²: pp. 99121.

Tushnet, Mark (2004): "Interpreting Constitutions Comparatively: Some Cautionary Notes, with Reference to Affirmative Action", Connecticut Law Review, vol. 36 N³: p. 649.

Valdés Prieto, Domingo (1992): La Discriminación Arbitraria en el Derecho Económico (Santiago, ConoSur Ltda.).

Vivanco, Ángela (1999): "La Garantía Constitucional de la Igualdad ante la Ley: ¿De qué Igualdad Estamos Exactamente Hablando?”, Revista Chilena de Derecho, vol. $26 \mathrm{~N}^{\circ} 1$ : pp. 173-186.

Westen, Peter (1982): “The Empty Idea of Equality”, Harvard Law Review, vol. 95 № 3: pp. 537-596.

Westen, Peter (1990): Speaking of equality (Princeton, Princeton University Press).

Williams, Melissa (1998): Voice, Trust and Memory (Princeton, Princeton University Press).

WiLson, John (1966): Equality (London, Hutchinson).

Young, Iris (2000): Inclusion and Democracy (Oxford, Oxford University Press).

\section{DOCUMENTOS ELECTRÓNICOS}

McCrudden, Christopher y Prechal, Sacha (2009): "The Concepts of Equality and Non-Discrimination in Europe: A practical approach” Disponible en: <http://ec.europa.eu/ social/BlobServlet?docId=4553\&langId=en > 
SAdURSKI, Wojciech (2006): "Majority Rule, Legitimacy and Political Equality” Disponible en: <http://ssrn.com/abstract $=891087$

\section{NORMAS LEGALES CITADAS}

Constitución Política de la República.

Ley N $N^{\circ} 20.609$ del 24 de julio de 2012, Establece Medidas contra la Discriminación.

Convención Europea de Derechos Humanos

Convención Interamericana contra Toda Forma de Discriminación e Intolerancia

\section{JURISPRUDENCIA CITADA}

\section{NACIONAL}

Tribunal Constitucional, Rol No 1951-11

Tribunal Constitucional, Rol No $1254-08$

Tribunal Constitucional, Rol No 986-07

Tribunal Constitucional, Rol No 811-07

Tribunal Constitucional, Rol No $807-07$

Tribunal Constitucional, Rol No 280-98

Tribunal Constitucional, Rol No 219-95

Tribunal Constitucional, Rol No $28-85$

\section{INTERNACIONAL}

Corte Europea de Derechos Humanos, Méndez Pérez y otros con España

COMPARADA

Consejo Constitucional Francés CC 2011/222

Consejo Constitucional Francés CC 2007/557

Consejo Constitucional Francés CC 2006/533

Consejo Constitucional Francés CC 2001/445

Consejo Constitucional Francés CC 92/316

Consejo Constitucional Francés CC 91/291

Consejo Constitucional Francés CC 91/290

Consejo Constitucional Francés CC 89/266

Consejo Constitucional Francés CC 87/232

Consejo Constitucional Francés CC 82/146

Consejo Constitucional Francés CC 80/128

Consejo Constitucional Francés CC 79/107

Corte Suprema Mexicana, AC 63/2009

Corte Suprema Mexicana, AC 21/2009

Corte Suprema Mexicana, AC 2/2002

Corte Suprema Mexicana, ADR 537/2006

Corte Suprema Mexicana, ADR 988/2004 
Corte Suprema Mexicana, AR 846/2006

Corte Suprema Mexicana, AR 55/2006

Corte Suprema Mexicana, AR 1959/2004

Corte Suprema Mexicana, AR 1629/2004

Tribunal Constitucional Español, STC 13/2009

Tribunal Constitucional Español, STC 12/2008

Tribunal Constitucional Español STC 200/2001

Tribunal Constitucional Español STC 269/1994

Tribunal Constitucional Español STC 16/1994

Tribunal Constitucional Español STC 216/1991

Tribunal Constitucional Español STC 20/1986

Tribunal Constitucional Español STC 86/1985

Tribunal Constitucional Español STC 34/1981

Tribunal Constitucional Español STC 22/1981 
